\title{
A Chronological Perspective on the Acheulian and Its Transition to the Middle Stone Age in Southern Africa: The Question of the Fauresmith
}

\begin{abstract}
Andy I. R. Herries
Australian Archaeomagnetism Laboratory, School of Historical and European Studies, Faculty of Humanities and Social Sciences, La Trobe University, Melbourne, VIC 3086, Australia

Correspondence should be addressed to Andy I. R. Herries, andyirherries@gmail.com

Received 8 November 2010; Revised 25 January 2011; Accepted 27 March 2011

Academic Editor: Parth Chauhan

Copyright ( $) 2011$ Andy I. R. Herries. This is an open access article distributed under the Creative Commons Attribution License, which permits unrestricted use, distribution, and reproduction in any medium, provided the original work is properly cited.

An understanding of the age of the Acheulian and the transition to the Middle Stone Age in southern Africa has been hampered by a lack of reliable dates for key sequences in the region. A number of researchers have hypothesised that the Acheulian first occurred simultaneously in southern and eastern Africa at around 1.7-1.6 Ma. A chronological evaluation of the southern African sites suggests that there is currently little firm evidence for the Acheulian occurring before 1.4 Ma in southern Africa. Many researchers have also suggested the occurrence of a transitional industry, the Fauresmith, covering the transition from the Early to Middle Stone Age, but again, the Fauresmith has been poorly defined, documented, and dated. Despite the occurrence of large cutting tools in these Fauresmith assemblages, they appear to include all the technological components characteristic of the MSA. New data from stratified Fauresmith bearing sites in southern Africa suggest this transitional industry maybe as old as 511-435 ka and should represent the beginning of the MSA as a broad entity rather than the terminal phase of the Acheulian. The MSA in this form is a technology associated with archaic H. sapiens and early modern humans in Africa with a trend of greater complexity through time.
\end{abstract}

\section{Introduction}

In the most recent reorganisation of the Pleistocene period $(2.58 \mathrm{Ma}-0.01 \mathrm{Ma}[1])$, the Ionian is defined as a geological stage between the Bruhnes-Matuyama boundary at $781 \mathrm{ka}$ (end of the Calabrian stage 1.81-0.78 Ma) and the beginning of Marine Isotope Stage 5 interglacial period at $126 \mathrm{ka}$ (beginning of the Upper Pleistocene 126-11.7 ka). Just prior to this is a period termed the Mid-Pleistocene Transition (or revolution [2]). This is the transition from what is known as the $41 \mathrm{ka}$ world to the $100 \mathrm{ka}$ world, essentially a switch from $41 \mathrm{ka}$ to $100 \mathrm{ka}$ cyclicity in glacial cycles [2]. This led to major environmental changes in Africa from about 1.0 Ma to $700 \mathrm{ka}$ [2]. The Ionian is also a period when a broad group of potential modern human ancestors attributed to "archaic Homo sapiens", (or more specifically to Homo heidelbergensis, Homo helmei, or Homo rhodesiensis) evolved to become the first anatomically modern humans. Noonan et al. [3] suggest that the split between Neandertal and ancestral $H$. sapiens populations occurred at $\sim 370 \mathrm{ka}$ and that divergence from a last common ancestor occurred at $\sim 706 \mathrm{ka}$. In Europe, $H$. heidelbergensis fossils such as those from Sima de los Huesos at $530 \mathrm{ka}$ [4] may represent fossils occurring soon after this initial split from a common ancestor.

In Africa, (Figures 1 and 2), the hominin record is more fragmentary and less well dated. The Kabwe (Broken Hill 1) hominin remains from Zambia may represent a similar postdivergence population in Africa, as might the Elandsfontein hominin remains from South Africa; however, the age of these fossils remains uncertain. The fauna from Kabwe is suggested to be broadly similar to Bed III-IV at Olduvai $(>1.07 \mathrm{Ma}$ or $>780 \mathrm{ka}[5,6])$ although its association to the type specimen of Homo rhodesiensis [7] is questionable and some age estimates are as young as $125 \mathrm{ka}$. The Elandsfontein hominin remains are contemporary with a "Cornelian Land Mammal Age" faunal assemblages in southern Africa [8], which date to between $\sim 1.1$ and $0.8 \mathrm{Ma}$ at other sites (Cornelia-Uitzoek; Buffalo Cave; [9, 10]) and represent 


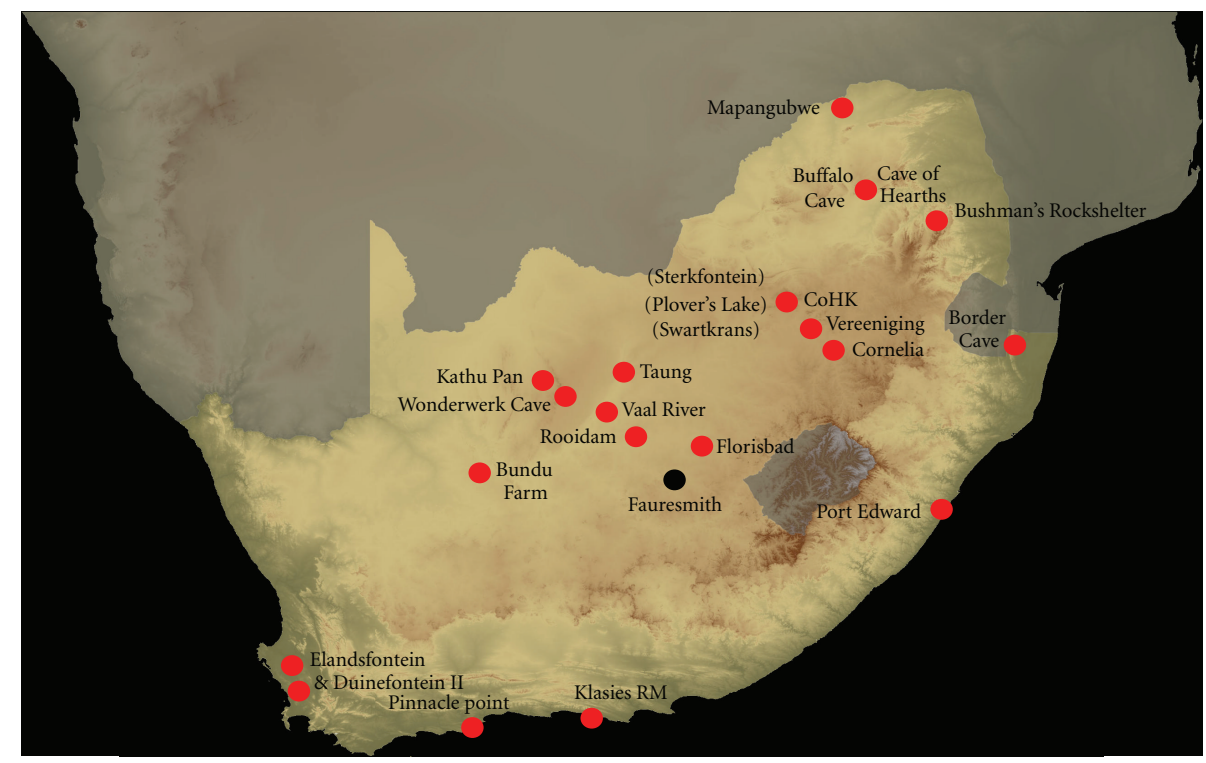

Figure 1: Location of sites discussed in the text within Africa.

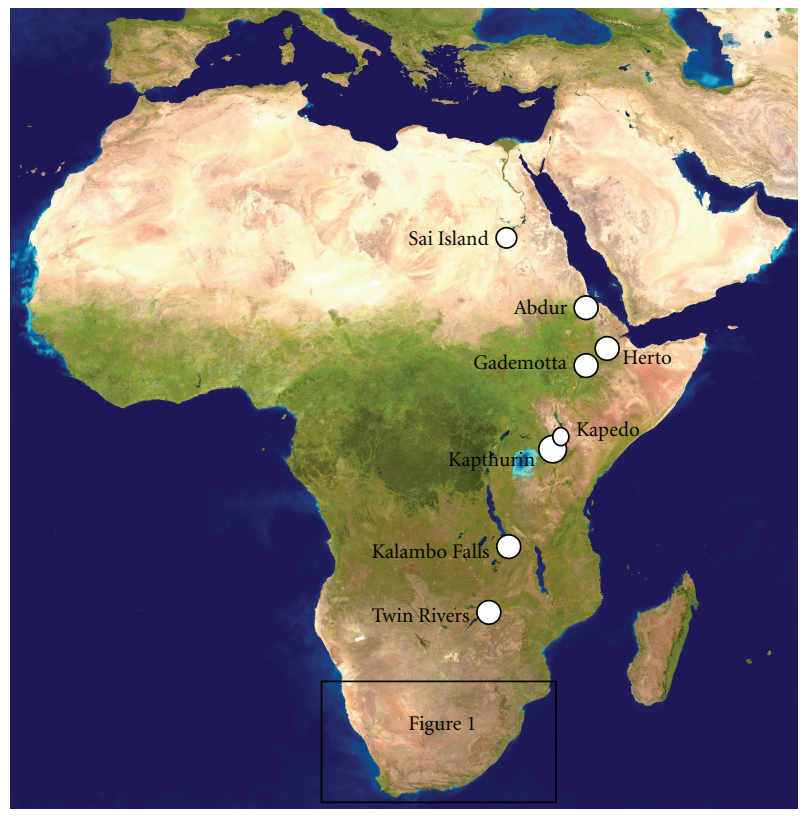

Figure 2: Location of the sites discussed in the text.

either Homo erectus or $H$. rhodesiensis. In contrast, the Florisbad hominin skull (the type specimen of Homo helmei [11]) is associated with a "Florisian Land Mammal Age" (see [8] FLMA; 780- 10 ka) faunal assemblage and MSA technology and is dated to $\sim 259 \mathrm{ka}[12,13]$. The oldest FLMA assemblage comes from Gladysvale Cave at between 780 and $578 \mathrm{ka}$ [14]. Currently, the earliest well-dated Homo sapiens remains come from Omo and Herto in Ethiopia between 198 and $147 \mathrm{ka}[15,16]$. In southern Africa, the oldest modern human remains come from Border Cave, Klasies River Mouth, and Pinnacle Point and are all dated to less than $184 \mathrm{ka}$ [17-20]. The Border Cave 1 and 2 remains could be as old as 184-143 ka based on ESR and depending on their actual provenience, while BC5 is somewhere between 79 and $69 \mathrm{ka}$ [19]. The Pinnacle Point remains are likely between 170 and $91 \mathrm{ka}$ although again, their provenience is uncertain [17, 18]. The oldest Klasies River Mouth remains from layer LBS are likely around $115-110 \mathrm{ka}$, while the younger SAS layer fossils are likely around 90-75 ka [20]. Fish Hoek Man (Peers Cave P4), once thought to be an early modern human, has recently been radiocarbon dated to $7.8-7.6 \mathrm{kcal} \mathrm{yr} \mathrm{BP} \mathrm{[21].}$

The Ionian is also a period when we see the transition from the Early to the Middle Stone Age (MSA) and the end of the Acheulian Industry in Africa. This is generally defined as a change from large cutting tools (LCTs) such as hand axes and cleavers to the use of blades, points, and prepared core technology, specifically the Levallois method [22]. An understanding of both the archaeological and hominin transitions in southern Africa has been hampered by a lack of reliable dated sites in the region. The current data suggest that the earliest MSA in both eastern and southern Africa is not associated with anatomically modern humans but with archaic Homo sapiens also referred to as H. helmei at sites such as Florisbad [13, 23] and Eyasi Springs [24]. Many researchers [25-28] have suggested the occurrence of a number of transitional industries in southern Africa, namely, the Fauresmith and the Sangoan, covering this transition, but they have generally been poorly defined, documented, and dated. The Fauresmith is generally considered to have aspects of both MSA and ESA technology and is most often defined as a terminal phase of the Acheulian [29]. The Sangoan is characterised by a heavy-duty, less-elegant component of picks and steep, sometimes denticulated scrapers as well as LCTs and MSA elements. Both the Sangoan and the Fauresmith have long been considered to mark the beginning of regional cultural specialisations towards the end of the ESA [28]. The Fauresmith, with its MSA-like features, perhaps holds the key to understanding this transition and 
the relationship between the archaeological and hominin record of this transitional time period between the ESA and MSA.

\section{History of the Fauresmith Industry and Issues of Terminology}

Creating an all-encompassing term for the definitive Acheulian artefacts, the hand axe, and the cleaver is in itself a problem. The term "hand axe" alone does not encompass cleavers, while biface does not take account of size, and many cleavers and hand axes are unifaces, being made from a single large flake and unretouched on the dorsal face. Large cutting tools (LCTs) is perhaps the best term and has been used elsewhere $[30,31]$. This term is used throughout to denote hand axes and cleavers of Acheulian character unless referring to a specific type of stone tool.

Goodwin [32] first split the Palaeolithic of Africa into three divisions, namely, the Early, Middle, and Later Stone Age (ESA, MSA, and LSA). Industries such as the Still Bay typified the MSA, where the most prominent artefacts were triangular flakes with convergent dorsal scars and faceted butts ("platforms"). The ESA was characterised by LCTs as seen in the Stellenbosch Culture, first found at the type site of Bosman's Crossing in Stellenbosch (Western Cape) in 1899 [33]. These deposits were later resampled by Hilary Deacon and James Brink, and there is now an attempt to date them by the latter and this author. The Stellenbosch was officially recognised by the Annual General Meeting of the South African Association for the Advancement of Science in 1926 [34]. The Stellenbosch was later incorporated into the term "Chelles-Acheul" as used in Eastern Africa or simply "Hand axe Culture". Leakey [35] also used the terms Chellean and Acheulian separately. The Chellean was essentially an industry between the Oldowan and Acheulian which did not have cleavers, only hand axes. This was later shown not to be the case [36], and the term Acheulian was then used alone.

Goodwin [32] saw the ESA as a natural unit characterised by hand axes. The formation of the MSA was a splitting of a single entity (the LSA) into two with the LSA containing flakes with parallel dorsal scars and smooth butts and/or by microliths (note that it was the MSA style of tools that were originally classified as the LSA). While the type site for the Stellenbosch were the alluvial deposits of Bosman's Crossing in Stellenbosch [33], the Vaal River gravel deposits (Northern Cape) have perhaps the greatest number of examples of what is now termed Acheulian. Other well-established Acheulian sites are Cornelia-Uitzoek $[10,37]$ and several sites near Vereeniging [38] in the eastern Free State as well as a number of caves sites discovered slightly later including Sterkfontein (Gauteng [39]), the Cave of Hearths, and Olieboompoort (Limpopo; Mason [36] and Montague Cave (Western Cape; [40]).

Goodwin [32] included the Fauresmith in the ESA along with the Stellenbosch and Victoria West Industries. Goodwin notes that these are all primarily core industries and that the chief instrument is the "coup-de-poing", that is, the hand axe. Goodwin [32] notes that raw material has a profound influence in the Stellenbosch with bad material yielding bad implements, while more workable material yielded finer implements. The Victoria West Industry was classified as having hand axes but with a large core that was made to produce a single large flake, the classic Victoria West Core. There has been much debate regarding the relationship of the Victoria West technology to other prepared core technologies (PCTs), notably Levallois PCTs [41-43]. The Victoria West Industry was later described as a technique within the final phases of the Stellenbosch rather than an Industry in its own right.

The Fauresmith takes its name from the town of Fauresmith in the south-western Orange Free State (Figure 1). The first description of the Fauresmith was given by Goodwin [44] when in a brief reference, he described it as essentially hand axes made on flakes. He notes that "it is difficult as yet to say how far this can be classed as an industry and how far it is only a local variation of the Stellenbosch". Goodwin [32] felt that the Fauresmith was a specialised branch of the Stellenbosch, while van Riet Lowe [45] thought it was perhaps a more regional variant related to the presence of indurated shale or that it was cultural, due to the arrival of new people into South Africa. While the Fauresmith may be a regional variant confined to the Free State and Northern Cape regions, surface collections from the site of Hopefield (aka Elandsfontein) were also called Cape Fauresmith. The term Southern Rhodesian Fauresmith has also been used [26], suggesting a wider occurrence of this industry. Moreover, the site of van der Elst Donga, near Vereeniging [46], is in Gauteng and extends the Fauresmith laterally across most of South Africa. Attempts are also being made to date these occurrences by the current author. The lack of Fauresmith industries may also be simply related to deposits of that age not being found in other areas.

In the first paper devoted exclusively to the Fauresmith, Van Riet Lowe [25] elaborated more on this culture. He said "...it represents the culminating phase of the Earlier Stone Age and, incidentally, the transition from core to flake treatment.... With the greater use of flakes, we come in contact with an evolutionary process that shows marked improvement in technique, the introduction of less clumsy artefacts and the beginnings of a variety of attendant tools that were not in evidence". Goodwin [32] notes that the Fauresmith hand axes are made on a longitudinal flake. In contrast, while earlier Stellenbosh hand axes are also made on flakes, they are laterally struck. Prime examples of this can be seen in the "early to middle Acheulian" hand axes of Cornelia and the Vaal River (personal observation).

Goodwin [32] notes that in the Fauresmith, the flake is always struck from a point situated, where the butt of the hand axe would eventually lie and that it is the beginning of a true flake industry. Instead of flakes that are struck off during the making of the hand axe being made into unconventional implements, true flake cores make their appearance along with true flake implements with longitudinal trimming, including points. In this earlier description by Goodwin [32], there is no mention of the size of the hand axes, something often taken to define the industry [47]. However, Goodwin and van Riet Lowe [26] later state that the hand axes are generally small and a neat almond, sometimes ovate 
shape, and that triangular hand axes are exceedingly rare. Fauresmith hand axes are also stated to have a straight edge, often with an s-shaped twist and differing from the zig-zag edge so often apparent in the Stellenbosch [26]. They further state that the hand axes are far finer than the best seen in the Stellenbosch and that the first beginnings of the Levallois technique are potentially seen $[26,48]$. Along with these are discs, scrapers, slightly trimmed flakes, and points [26]. Moreover, Fauremsith flakes are suggested to typically have a faceted platform [26], as in the MSA.

In comparison, the MSA was characterised archaeologically in 1928 [49] by the absence of LCTs that characterise the ESA, an increased prevalence of prepared core reduction strategies, the production of projectile points, and a variety of flake-based tools. The oldest MSA industry was considered to be the Still Bay with its lanceolate points [48], now known to date to $\sim 72 \mathrm{ka}[50]$. Goodwin [32] also notes similarities between the Fauresmith and some MSA industries, for example, that the Glen Grey Industry (Eastern Cape) directly evolved from the Fauresmith. So, here, Goodwin [32] is noting distinct similarities between the MSA and the Fauresmith but chooses to align the latter with the ESA based on the occurrence of LCTs.

Sampson [51] noted that the Fauresmith has been primarily defined as an industry later than the Stellenbosch and containing smaller, more refined hand axes. However, in 1945, van Riet Lowe [52] suggested that "the progress of man's skill from Stellenbosch to Fauresmith times is thus not so much measured by a series of successive refinements in his hand axes and cleavers as by an abandonment of old methods and by an improved technical skill revealed in the greater refinement and variety of his waste products in the form of smaller and more elaborately prepared cores and flakes". Moreover, van Riet Lowe states [52] that it "is not the continued presence of hand axes so much as the integrally associated and now considerably improved [fully developed] Levallois technique" and "while many of the earlier Fauresmith hand axes are smaller and more refined than are their Stellenbosch proto-types, this group of implements is generally neither so beautifully made nor so varied as a representative group from the final Stellenbosch". Here van Riet Lowe sets out the differences between the Stellenbosch and the Fauresmith, which he $[52,53]$ divided into three stages.

In comparing the ESA and MSA in 1946, Goodwin [27] states simply that the ESA (meaning the Acheulian) is defined by the hand axe, while the MSA is defined by an accentuation of Levallois (notably used by Tryon et al. [54] to define the MSA) and preferably triangular or sector-shaped points. Goodwin suggests that while we are dealing primarily with techniques, each of these techniques is foreshadowed in the previous phase. We only reach each new "age" as the new technique becomes dominant and replaces previous modes [27]. It is not clear which dominates an interpretation in this scheme, the presence of LCTs or the refinement of new techniques. As such, this leans towards the idea of true intermediate periods as proposed by Clark in 1965 [55]. In 1954, Clark [56] noted the similarity of the Kalambo Falls material to the Fauresmith of South Africa. By 1964,
Clark [57] had begun to see the Fauresmith as essentially a southern African (with pockets in Eastern Africa) entity that was in essence the survival of earlier Acheulian traditions, south of the Limpopo. In central and central southern Africa (i.e., Zambia), the addition of heavy chopping tools and small denticulates was termed the Sangoan. It seems possible that the Sangoan as described by Clark at Kalambo Falls represents a transitional Acheulian to MSA industry that occurred in more forested areas, whereas the Fauresmith occurred in more open savannah and thornvelt environments. Clark suggested that the Sangoan/Fauresmith represents an intermediate period between the final Acheulian and the MSA, which he terms the "first intermediate period". At the 1955 Panafrican Congress, the term "First Intermediate Period" was adopted to describe this transition period between the ESA and MSA, but the term was then dropped at the Burg Wartenstein symposium of 1965 [58].

Based on his work in the Transvaal, Mason [39] suggested that all the hand axe cultures and developed Oldowan be assumed under the term Acheulian. Mason [39] notes that he "discontinues the use of the term Fauresmith for the last known phase of the Acheul sequence in the Transvaal, for, like Chellean' it obscures the close relationship industries such as the Cave of Hearths Earlier Stone Age series have with the Acheul". In this statement, Mason [39] is setting out that the Fauresmith holds greater similarity to the Acheulian than the MSA. Mason [39] also notes that there "is no factual stratigraphic support for the three stage division of the Fauresmith". He was in favour of simply using early (Sterkfontein, etc.), middle (Vaal River), and later (Cave of Hearths) Acheulian and abandoning the term Fauresmith for the final phase of the ESA. As Inskeep notes in 1969 [59], the trend at that time was for a reduction of names referring to different regional variants of stone tool industries. That is, incorporation of the Stellenbosch into the Acheulian and removal of the Victoria West into a technique rather than an industry. But he also notes that "while hand axes and cleavers maybe characteristic they are by no means the only tools of the Acheulian and not the most numerous". Going further, Humphreys [60] argues that all the tool types found within the Fauresmith are also found in the Acheulian.

Humphreys [60] notes that the distribution of Fauresmith and Stellenbosch sites raises two important points. The first is that most of the Stellenbosch sites are associated with the Vaal River area, while all but two of the Fauresmith sites are well away from that river, perhaps suggesting differences related to activities, raw materials, or even survival in different geological contexts. Humphreys [60] also notes that the correlation of Stellenbosch and Fauresmith occurrences with the different types of raw materials suggested by the distribution of sites seems too clear to be accidental. Humphreys [60] tries to take consideration of this and cites Mason's [61] work at the Cave of Hearths as an example of a late Acheulian industry contemporary with the Fauresmith that suggests the latter is a regional or raw materialspecific variation. Indeed Mason [61] originally called the assemblage Fauresmith, in part based on the occurrence of small hand axes but later changed it to Acheulian [39]. While the Fauresmith occurrences have been shown to be clearly 
stratified above Acheulian deposits, Humpreys believes this is perhaps due to a lack of recovery or survival of artefacts in the gravel contexts compared to the sand contexts as at Canteen Kopjie. Excavations by Gibbon [62] and Leader [63] have shown that the small fraction is preserved in Acheulian bearing gravel deposits in the Vaal River, so this question can now begin to be tested with other recent Fauresmith excavations at Canteen Kopjie, Wonderwerk,and Kathu Pan, as will be discussed below.

Returning to van Riet Lowe, in 1945 [52], he suggested that "throughout the Fauresmith we have three principal types of cores, the majority with prepared striking platforms: (a) circular or tortoise cores, (b) triangular flake-cores, and (c) rectangular blade-cores. Giant blades are also noted (foot long). The makers of Fauresmith tools were not only masters of a fully developed Levallois techniquebut specializedin flake tools of considerable variety. In the final stages the hand-axe became less and less important and was gradually superseded and replaced by other types of tools until....we cannot say whether we are at the end of the Earlier or at the beginning of the Middle Stone Age." "This final Fauresmith is literally a period of transition and is distinguished only by the presence of hand axes; the remaining tools and debitage being completely Middle Stone Age in form and fineness". In 1952, van Riet Lowe [53] further suggested that the Fauresmith showed "the earliest local use of the mounted tool in the form of a spear", something most researchers would equate with the MSA, not the ESA.

Here, van Riet Lowe [53] appears to be stating that the only difference between the late Fauresmith and the MSA is the continued presence of LCTs, and this could be used to suggest that the Fauresmith should be included within the MSA rather than the ESA and that an industry should be defined on new technology rather than the continued use of old technology. The idea that transitional industries such as the Fauresmith and Sangoan have more in common with the MSA is a view since put forward by Davies [64], Van Peer et al. [65], and Beaumont and Vogel [47], the latter of which suggests the Fauresmith should be termed early MSA (EMSA) and assemblages without LCTs later MSA (LMSA). In van Riet Lowe's 1937 [45] definition of the 3 phases of the Fauresmith, the 1st phase was described as having "hand axes, cleavers, crude scrapers and cores that yielded long, narrow flake". This is not dissimilar from the Acheulian that we now know and likely represents the end phase of the Acheulian. The 2nd Fauresmith phase was described as "comprising beautifully finished hand axes on flakes, cleavers, trimmed points, end- and side-scrapers, typical concavo-convex side scrapers, typical levallois flakes and cores: long and slender blades cores, faceted polyhedral stones and gravers." And the "hand axes are generally well made with straight edges and well controlled flaking". This is the typical mixture of ESA and MSA elements that is perhaps the best definition of the Fauresmith as an Industry or at least of Clark's First Intermediate Period [55].

As will be described below, recent studies suggest that the so called Fauresmith industry, and others, has a great deal in common with the MSA and perhaps the occurrence of the first elements of the MSA rather than the remaining elements of the Acheulian within the Fauresmith should be the most important factor in (a) defining it as its own transitional entity and (b) including it within the MSA rather than the Acheulian. It is quite possible that some of the Fauresmith being described is material that has since been defined as early MSA. Only a chronological analysis of these sites to assess their contemporaneity would help resolve these issues.

\section{The Early Acheulian in Southern Africa}

To fully understand the context and difference of the Fauresmith, an overview of the Acheulian record in southern Africa is first needed. Well-dated Acheulian sites are still few and far between in southern Africa mostly due to the difficulty of dating caves and river sequences, where much of this material is preserved. Acheulian sites often occur on deflated landscapes rather than in well-stratified and datable contexts and even then reliable means of dating such contexts were unavailable until recently. Moreover, many Acheulian assemblages come from reworked contexts rather than primary occupations. The most extensive Acheulian bearing deposits are the numerous palaeocave sites within the Cradle of Humankind World Heritage Area in Gauteng (CoHK, e.g., Sterkfontein, Swartkrans, and Kromdraai [66, 67]), donga sequences of the Free State (e.g., Vereeniging and Cornelia [10, 38]), the Vaal River sites (e.g., Pneil and Canteen Kopje [68]), a series of Pan deposits around Kimberley (e.g., Kathu Pan and Rooidam $[69,70]$ ), dune sequences of the western Cape coast (e.g., Elandsfontein and Duinefontein II [71]), and a series of isolated caves occurring throughout the country (e.g., Wonderwerk Cave in Northern Cape, the Cave of Hearths in Limpopo Province, and Montagu Cave in Western Cape [40, 47, 72]). Other localities include Amanzi Springs in Eastern Cape [73] and a series of sites in the Mapangubwe National Park along the Limpopo River (Limpopo Province; [74]).

Three phases of the Acheulian have been defined based on typology [45]. Kuman [66], Chazan et al. [75], and Gibbon et al. [76] have all suggested that the early Acheulian first occurs in southern Africa around 1.6 Ma coeval with its occurrence in Eastern Africa. While a review of the dating makes this possible, the refinement of the dating is perhaps too coarse to currently make this statement. Kuman and Clarke [77] have argued for the Acheulian from Sterkfontein Member $5 \mathrm{c}$ being as early as $1.7-1.4 \mathrm{Ma}$ based on faunal comparisons. However, a recent comparison of fauna, palaeomagnetic, electron spin resonance (ESR), and uranium-lead (U-Pb) age estimates $[67,78,79]$ have suggested that the Acheulian deposits are more likely dated to between 1.3 and $1.1 \mathrm{Ma}[80]$. The robust nature of the ESR ages is supported by identical age ranges for Member 4 (2.6$2.0 \mathrm{Ma}$ ) based on independent ESR, palaeomagnetism, and uranium-lead analyses [79-81] as well as geochronological comparisons at other sites in the cradle (see below). Moreover, the StW 53 infill (aka Member 5a) at Sterkfontein has been shown to be older than the Member $5 b$ and $5 c$ deposits based on stratigraphy and geochronology $[79,81,82]$. The StW 53 infill has been dated to $<1.78 \mathrm{Ma}$ based on a U-Pb age for speleothem that formed before the deposition of Member 
$5 \mathrm{a}$ and the reversed magnetic signal of this deposit [79]. ESR ages are again consistent with this and taken together an age between 1.8 and $1.5 \mathrm{Ma}$ is most likely [67, 79]. Given this data, there is no definitive reason based on the current data to discount the ESR ages for the Member $5 c$ Acheulian.

O'Regan and Reynolds [83] suggest that the diversity of carnivore species in the deposit indicate that it is a palimpsest formed over a long period of time. The spread of ESR ages may support this suggestion. Given this suggestion and taking the maximum age range for all the ESR ages into account, rather than a weighted mean age as per [79], a maximum age range of $1.39-0.82 \mathrm{Ma}$ is suggested for the Acheulian, and so, it is not older than $1.4 \mathrm{Ma}$ (The M5b deposit has a maximum ESR range of 1.62-0.83 Ma (minus a single age with an extremely large error) and suggests that the Oldowan is not older than $1.6 \mathrm{Ma}$ at Sterkfontein). The age for the Acheulian is at the lower age range of Kuman and Clarke's [77] estimate. While some fauna from Sterkfontein Member 5 suggests an older age, the fauna collections are likely quite mixed due to numerous years of excavation into the deposits (see [79]) without understanding their complexity. Vrba [84] previously suggested the fauna from Member 5 was likely around $1.5 \mathrm{Ma}$, and a reanalysis of the carnivores from Member $5 \mathrm{c}$ has suggested that it is likely younger than previously suggested [67, 85]. O'Regan [85] suggests that the only older element in Member 5c, Dinofelis barlowi, likely does not come from Member 5. O'Regan [85] notes that a number of archaic carnivores (Megantereon and Chasmaporthetes) are present in Swartkrans Member 1 but not in Sterkfontein Member 5 despite the fact that they are generally considered contemporary. Herries et al. [67] suggest that Swartkrans Member 1 maybe around 2.1-1.9 Ma, and so, this may be a temporal difference. Pickering et al. [86] have recently suggested that the Hanging Remanent at Swartkrans is dated to sometime between 2.2 and $1.8 \mathrm{Ma}$. These temporal changes may explain some of the O'Regan [85] hypothesises that this might be related to taphonomic differences, different ages or different environments being sampled. Given that the caves are across the valley from each other the environment would likely be similar if of the same age. Taphonomic reasons can never be ruled out; however, given the new younger ESR ages for Member 5b/c (1.4$1.1 \mathrm{Ma})$ and the suggested older age for Swartkrans Member $1[67,86]$, this difference, and differences noted by Reynolds [87], is likely to be partly a reflection of age.

Kuman and Clarke's [77] age assessment is also in part due to the fact that the LCTs from Sterkfontein M5c are both limited in number and very unrefined. The earliest date for an assemblage assigned to the Acheulian is often quoted as $\sim 1.7 \mathrm{Ma}$ at locality KGA of Konso Gardula in Ethiopia [88]. However, the earliest Acheulian deposits occur in deposits dated to somewhere between 1.69 and $1.41 \mathrm{Ma}(1.66 \pm$ $0.03 \mathrm{Ma}$ and $1.43 \pm 0.02 \mathrm{Ma}$; [89]. The first Acheulian tools occur closer to 1.4 Ma than 1.7 Ma based on the stratigraphy and the occurrence of a stratigraphic break between the hand axe horizons and the basal age [90]. While the KS4 site from the Nachukui Formation (West Lake Turkana, Kenya) is suggested to have an age slightly older than 1.65 Ma [91], the majority of other early Acheulian sites in Eastern Africa are generally dated to less than 1.5 Ma including Olduvai Gorge, middle and upper Bed II (1.53-1.27 Ma; [92]), to which many of the southern African early Acheulian deposits are often compared [93]. As such, there seems little typological basis for the Sterkfontein Member 5 Acheulian being at the older part of the 1.7-1.4 Ma age range as suggested by Kuman $[66,93]$. Moreover, it is not unreasonable to assume that the Acheulian may first occur later in southern Africa than it does in Eastern Africa, as is the case for other parts of Africa or the Levant, where it does not occur until somewhere between 1.5 and 1.2 Ma [94].

Acheulian tools are also known from Swartkrans Member 2 and 3 dated to sometime between 1.65 and $0.6 \mathrm{Ma}$ [67]; however, Swartkrans remains one of the least well-dated site in the CoHK and many of the other sites have relatively undiagnostic stone tool assemblages [66]. Many, including Swartkrans Member 1, have been classified as Developed Oldowan or early Acheulian based on the fact that many have no LCTs, but a large flake size than the preceding Oldowan $[66,95]$. However, the recent dating suggests that parts of Swartkrans Member 1 are as old as $2.2-1.8 \mathrm{Ma}[67,86]$, making an assessment of these stone tools as Acheulian perhaps less likely [67]. That being said, Swartkrans Member 1 may be more complex than previously noted with multiple in-fills of more than one age.

Gibbons et al. [76] have suggested that Acheulian stone tools in the Rietputs (Rietputs 15) formation of the Vaal River are also dated to $\sim 1.6 \mathrm{Ma}$. These deposits have maximum ages between 2.08 and $1.12 \mathrm{Ma}(1.89 \pm 0.19 \mathrm{Ma}$ and $1.34 \pm 0.22 \mathrm{Ma})$ and minimum ages between 1.88$1.08 \mathrm{Ma}(1.72 \pm 0.16 \mathrm{Ma}$ and $1.29 \pm 0.21 \mathrm{Ma})$ suggesting that the LCA gravel deposits date to between $\sim 2.1$ and $\sim 1.1 \mathrm{Ma}$. The LCA gravel deposits are up to $4 \mathrm{~m}$ deep in some of the pits sampled and up to $7 \mathrm{~m}$ thick overall and appear to have accumulated over perhaps a million years. The stone tools collected come from an undated pit and were collected out of context from mining debris piles and sporadically from an excavating conveyor belt over two days of 24 hour operation [76]. As such, the Rietputs Acheulian described by Gibbon et al. [76] could come from anytime during the deposition of the LCA deposits. The later collected Acheulian assemblage described by Leader [63] comes from Pit 5, and so dates to somewhere between 1.63 and $1.11 \mathrm{Ma}(1.43 \pm$ $0.23-1.32 \pm 0.21 \mathrm{Ma})$. Note that $\sim 1.6 \mathrm{Ma}$ is at the extreme upper end of this age range, and a more likely age for this assemblage is perhaps $1.4-1.3 \mathrm{Ma}$. A further collection described by Leader [63] came from an in situ excavation with no current ages. However, the stratigraphy of each of the pits and dating sample location compared to depth of the LCA is never presented in either Leader [63] or Gibbon et al. [76], making it difficult to confidently relate the ages to the artefacts collected beyond the age for the LCA as a whole, 2.0-1.1 Ma.

In Pit 2, the top of the LCA was dated to somewhere between 1.42 and $1.08 \mathrm{Ma}(1.27 \pm 0.15-1.22 \pm 0.14 \mathrm{Ma})$, and the overlying UFA has been dated to somewhere between 1.45 and $1.01 \mathrm{Ma}(1.26 \pm 0.19-1.16 \pm 0.15 \mathrm{Ma})$ suggesting that the LCA deposits are more likely older than $\sim 1.2 \mathrm{Ma}$. For some reason, Gibbon et al. [76] and Gibbon [62] included 
the sample from the top of the LCA [72, Table 1] within the overlying UFA when calculating the mean burial age for the LCA deposit. This will have had the effect of very slightly increasing the mean maximum age estimate for the LCA deposits from 1.53 to $1.57 \mathrm{Ma}$. Moreover, this is the maximum mean age for the deposits. Based on erosional history, Gibbon et al. [76] suggest the true age is likely closer to the maximum age estimate; however, this is by no means certain, and an age between the maximum and minimum age estimates is also perfectly possible. As such, some Acheulian deposits from the Vaal River could be as old as $1.6 \mathrm{Ma}$ or older, but the age of the collections described by Leader [63] is closer to $\sim 1.4-1.3 \mathrm{Ma}$.

Cosmogenic burial ages for the base of the Canteen Kopjie Acheulian bearing lower coarse alluvium (stratum 2b) range between 1.25 and $0.82 \mathrm{Ma}(1.06 \pm 0.19 \mathrm{Ma}$ and $1.00 \pm$ $0.18 \mathrm{Ma})$ in one pit and 1.61 and $1.23 \mathrm{Ma}(1.46 \pm 0.15 \mathrm{Ma}$ and $1.37 \pm 0.14$ ) in a second pit [62]. Gibbon [62] notes that these ages suggest that deposition of the gravels was very complex on a local scale (within $40 \mathrm{~m}$ ), and as such, ages from one location may not represent the age of deposits on a locality scale. As such, for reliable dates of assemblages from the gravels, the levels need to be dated directly in each case, and as the collection described by Gibbon et al. [76] comes from an undated pit, the age of the stone tools is much less certain.

Chazan et al. [75] also suggest an age of $\sim 1.6 \mathrm{Ma}$ for the beginning of the Acheulian at Wonderwerk butagain this age is by far from secure. The Acheulian first occurs in sediments (strata 11) that are dated to somewhere between 1.78 and 1.07 Ma based on palaeomagnetism and a basal cosmogenic isotope burial age [75]. A number of depositional breaks appear to occur in the sequence, notably between the layers recording the palaeomagnetic transition at the end of the Oldowan (1.78 Ma; strata 12$)$ and the layers containing the Acheulian (strata 11). This may suggest the material is closer to $1.07 \mathrm{Ma}$ than $1.78 \mathrm{Ma}$. The Vaal River and Wonderwerk Cave early Acheulian may date to as old, or in theory older than $1.6 \mathrm{Ma}$, but could be closer in age or contemporary with the Acheulian from Sterkfontein M5c at 1.4-1.1 Ma. As such, there is little definitive evidence for the Acheulian in South Africa older than 1.4 Ma. Hominin fossils are rare, but these earliest Acheulian occurrences are normally associated with Homo ergaster [77].

Recent palaeomagnetic studies at the Cornelia-Uitzoek locality have shown that multiple levels of Acheulian bearing deposits occur there between 1.07 and $0.78 \mathrm{Ma}$ [10]. The oldest Acheulian layers at Elandsfontein may also be of a similar age, and Klein et al. [5] suggest that Elandsfontein dates to somewhere between 1.0 and $0.6 \mathrm{Ma}$. However, Klein et al. [5] suggest that the site most likely dates closer to $600 \mathrm{ka}$ based on the presence of Rabaticeras and Pelorovis antiquus, the hominin remains, and the typology of the Acheulian artefacts. Klein et al. [5] suggest that the extinct alcelaphine Rabaticeras likely gave rise to the extant hartebeest genus, Alcelaphus which has a first appearance date close to $600 \mathrm{Ka}$, based on its occurrence at Bodo and that the extinct longhorned buffalo Pelorovis antiquus has a first appearance at or soon after $1 \mathrm{Ma}$ based on its evolution from Pelorovis oldowayensis after the deposition of Olduvai Bed IV. Bodo is dated to sometimes between 690 and $520 \mathrm{ka}(630 \pm 30 \mathrm{ka}-$ $550 \pm 30 \mathrm{ka}[91])$. However, the Bodo material shows a lot of affinities to material from Olduvai bed IV at $>0.78$ $>1.07 \mathrm{Ma}[6,96]$. Moreover, Rabaticeras itself actually occurs at Buffalo Cave and Cornelia-Uitzoek, both of which are dated to between 1.1 and $0.8 \mathrm{Ma}[9,10]$. The remainder of the fauna from Elandsfontein is also similar to that from Cornelia-Uitzoek and Buffalo Cave, representing the Cornelian Land Mammal Age [10]. Also, Klein et al. [5] also note that the occurrence of Sivathere and the dirk-toothed cat which would have to represent the youngest occurrences of these species by some margin. This suggests that there is little evidence for Elandsfontein being younger than at least $0.8 \mathrm{Ma}$.

Also, in Western Cape, the Duinefontein II fauna also belongs to the Cornelian Land Mammal Age (Brink, pers. comm.). The site also contains an Acheulian estimated to date to between 347 and $217 \mathrm{ka}[71,97]$ based on a combination of thermoluminescence (TL), optically stimulated luminescence (OSL), and infrared-stimulated luminescence (IRSL). This is extremely young and of a similar age to some of the earliest MSA industries in South Africa (see below). Moreover, the Cornelian Land Mammal Age is followed by the Florisian Land Mammal Age, which is currently dated back to sometime between 780 and $578 \mathrm{ka}$ [14] at Gladysvale Cave. This, along with the faunal similarities to Elandsfontein, Buffalo Cave, and Cornelia-Uitzoek, may suggest that Duinefontein II shoul, in fact, be older than $800 \mathrm{ka}$, at odds with the luminescence age estimates. If the luminescence age estimates are correct, then this would indicate marked regional variation in the timing of the transition from the Cornelian to the Florisian Land Mammal Age and the Acheulian to the MSA. The Acheulian certainly lacks elements of the MSA as seen in Fauremsith assemblages despite Elandsfontein once being called Cape Fauresmith based on the small size and shape of some of its hand axes. However, Feathers [20] outlines the problems with the dating samples from this site. Based on the problems of variable dose rates and shifting dunes through time at this locality, these age estimates maybe underestimations of the true age of the deposits and should perhaps be regarded as minimum ages. These ages were also performed on feldspar whose luminescence signal is known to fade with time, causing younger age estimates [98] and redating using post IR-IRSL could be attempted. However, given the faunal age estimates, the site is likely also beyond the limit of this method. Future potential for the dating of the west coast sites comes in the form of thermally transferred OSL (TT-OSL), which can date back to at least $780 \mathrm{ka}$ if the correct conditions occur [99].

Gladysvale Cave has also yielded a single hand axe dated to older than $780 \mathrm{ka}[100,101]$. The age of the Bed 1-3 Cave of Hearths Acheulian is still a matter of debate, but it is certainly younger than $780 \mathrm{ka}$ based on palaeomagnetism [102]. McNabb [103] suggests that the Cave of Hearths assemblage is lacking elements suggestive of the Fauresmith or MSA such as Levallois and other prepared core technology points and blades. A direct ESR date on the mandible from Bed 3 suggests and age of 600-400 ka however there are issues 
with the dosimetry for this sample [104]. Given this ESR age and based on the age of confirmed geomagnetic field events [105], a short geomagnetic reversal in the basal deposits $[101,102]$ most likely dates to either the Big Lost event dated to between $580-560 \mathrm{ka}$ or the Stage 17 excursion at $\sim 670 \mathrm{ka}$. As such, the Bed 1-3 Acheulian from the Cave of Hearths, including the hominin remains, may date to the period between 700 and $400 \mathrm{ka}$ but most likely towards the older end of this age range. The fossils associated with these sites are often referred to as $H$. rhodesiensis, $H$. heidelbergensis, $H$. erectus, or simply archaic $H$. sapiens [29]. Taking $H$. erectus as an Asian origin species and $H$. hedelbergensis as a European origin species, the use of $H$. rhodesiensis is perhaps most appropriate for much of the African hominin record (as per $[22,23])$ of this time period. However, designation to a specific species should obviously be undertaken on a fossil by fossil basis, as there is always the possibility that species did not just leave Africa but that $H$. erectus and $H$. heidelbergensis may have migrated into Africa at various times.

\section{The ESA-MSA Transition in Eastern Africa}

In the older K3 deposits of the Kapthurin Formation (GnJh03, GnJh-17; <518 ka) Deino and McBrearty [106] document the use of LCTs, Levallois, and blades and a notable feature is the use of the Levallois technique to make hand axes. Johnson and McBrearty [107] describe a further small set of blades from the base of the K3 deposit (GnJh-42 and GnJh-50) at between $548(545 \pm 3 \mathrm{ka})$ and $500 \mathrm{ka}(509 \pm 9 \mathrm{ka})$ and suggest that the move to blade technology is a feature of the Acheulian period. While the blades are standardised Johnson and McBrearty [107] suggest the earliest blades are not made by the Levallois method. Refinement of the K4 sequence by Tyron and McBrearty $[108,109]$ indicates that $>272 \mathrm{ka}(284$ $\pm 12 \mathrm{ka}$ ) LCTs (cleavers) and Levallois technology occur at the same sites in the southern area, while LCTs produced from Levallois cores (e.g., at LHA) and points occur together in slightly older deposits in the northern area (e.g., at GnJh17). By $\sim 200 \mathrm{ka}$ (perhaps $250 \mathrm{ka}$ ) the site of Koimilot (also in the Kapthurin Formation) shows a range of Levallois flake reduction strategies including convergent Levallois flakes and points and an absence of LCTs $[109,110]$. Slightly further north between the Turkana and Baringo basins, much younger MSA assemblages occur in the Kapedo Tuffs [111]. These sites illustrate that by $135-120 \mathrm{ka}(132 \pm 3 \mathrm{ka}$ and $123 \pm 3 \mathrm{ka}$ ) a wide range of Levallois flake-based reduction techniques are being undertaken within the MSA [54]. As such, Levallois blade and point technology characteristic of the MSA occur at the same time as characteristic LCTs of Acheulian character. This sequence suggests the early occurrence of blades within the Acheulian before $500 \mathrm{ka}$. Points begin to occur towards the end of the K3 deposits sometime between 518 and $272 \mathrm{ka}$. At sites within the base of the K4 deposits, LCTs made from Levallois flakes occur at sites such as LHA and GnJh-17 [106]. Soon after this centripetal Levallois, flakes and cores occur at sites such as Rorop Lingop [106]. LCTs in the form of cleavers are then last seen in the middle of the K4 deposits at some time before $272 \mathrm{ka}$ [106]. After this ( 250-200 ka), at the site of Koimilot a range of Levallois flaking occurs including the presences of convergent Levallois flakes and points $[108,109]$. Tryon [110] uses this change in Levallois flaking behaviours at Koimilot as the beginning of the MSA despite tools of MSAlike character occurring earlier in the sequence. McBrearty [22] suggests that this sequence indicates an independent evolution of blades, points, and Levallois technology during the transition from the Acheulian to the MSA and that it does not occur as a package of behaviour evolving together. As such, this causes a major issue in defining exactly what the MSA is and when it might begin. As such, the diversification in Levallois technology is suggested as the defining features of the end of the ESA and beginning of the MSA around 250$200 \mathrm{ka}$ in the Kapthurin Formation.

Malewa Gorge in Kenya is another site where MSA (Kenyan Still Bay) has been recovered from beneath a tuff that was originally dated to $240 \mathrm{ka}$ [112]. Clark [55] suggested that if the Still Bay was older than $240 \mathrm{ka}$ the tuff samples dated must have been contaminated. An attempt at redating this tuff by Morgan and Renne [113] gave an age of $102 \pm 16 \mathrm{ka}$, much younger than the original age. PseudoStill Bay artefacts were also dated to $<557$ and $>440 \mathrm{ka}$ at Wetherill's and Cartwright sites and suggests that transitional industries could potentially occur here as early as half a million years [112].

Morgan and Renne [113] describe the dating of MSA and perhaps transitional ESA/MSA localities within the Gademotta Formation in southern-central Ethiopia. At the type site unit 9 of Laury and Albritton [114] lies beneath unit 10 which has been dated to sometime between 280 and $272 \mathrm{ka}(276 \pm 4 \mathrm{ka}$; G3; [105], and so, the earliest MSA is older than $272 \mathrm{ka}$. Unit 10 at the nearby site of Kulkuletti is dated to $280 \pm 8 \mathrm{ka}$, but this age is less precise [113]. However, an age of $193-173 \mathrm{ka}(183 \pm 10 \mathrm{ka})$ from here provides an age for younger MSA deposits [113]. Small Acheulian hand axesare found at the base of unit 9 [115], while from the upper part of Unit 9 and upwards, only MSA artefacts are found. These MSA artefacts include medium to large retouched points and scrapers, some of which were made by the Levallois method and many look quite advanced and like younger MSA assemblages in the region [113]. This is suggested to be in part due to the use of obsidian at these sites when compared to others like Kapthurin [112]. These artifacts display enormous variability in the sense of technology and retouched tool forms and neither the frequency of use of the Levallois technique nor tool size showed consistent change within the sequence ( $>272-173 \mathrm{ka}$; $[114,115])$. Despite the small hand axes in the base of unit 9 the Gademotta and Kulkuletti, MSA is suggested not to have an underlying Acheulian with characteristics of the Fauresmith or Sangoan [112].

Clark et al. [16] describe the remains of anatomically modern humans from the Upper Herto Member of the Bouri Formation, Middle Awash in Ethiopia dated to between $166 \mathrm{ka}(163 \pm 3 \mathrm{ka}$; MA98-25), and $147 \mathrm{ka}(154 \pm 7 \mathrm{ka}$; TG $120)$ that are associated with LCTs. Along with the Omo 1 fossil, these anatomically modern human remains represent some of the earliest in Africa. It should be noted that while $195 \mathrm{ka}$ is the often cited date of the Omo fossils, in reality, 
the fossils date to sometime between 198 and $97 \mathrm{ka}$ (196 \pm $2 \mathrm{ka} ; 104 \pm 7 \mathrm{ka}$ ) although they are argued to lie closer to the older age [15]. Millard [116] suggests an alternative age range based on the data of 191-98 ka but again stresses that the true age is likely closer to the older value. This could make them roughly contemporary with the Herto fossils rather than significantly older than them. Despite the young age, like the Kapthurin Formation, the Herto assemblage includes some LCTs being made from Levallois Flakes. MSA tools dated to around $125 \pm 7 \mathrm{ka}$ have also been recovered in association with LCTs and "Acheulian cores" at the site of Abdur in Eritrea [117]. Bruggemann et al. [117] suggest that this transitional industry indicates Acheulian and MSA technologies continued to coexist for much longer and that the Acheulian maybe widespread on the Red Sea coast from Egypt to Djibouti at this period. These two occurrences appear to represent the youngest occurrence of LCTs in Africa, but whether these stone tools are intrusive or reused Acheulian artefacts remains to be seen. No LCTs were recovered from in situ excavations at Herto and all the LCTs come from controlled surface collections.

The Sangoan (like the Fauresmith) has been classed as a final ESA industry, possibly about 300000 years old [23] although some researchers would classify it as a transitional industry or even an early MSA [30]. Van Peer et al. [65] describes a transition from the Acheulian, through Sangoan to the Lupemban-like MSA at site 8-B-11, Sai Island, Sudan. Maximum age estimates for the Sangoan deposits is based on OSL dating of the underlying aeolian ES sands between 242-204 ka (223 $\pm 19 \mathrm{ka}[65])$. Minimum age estimates are provided by an OSL age from above the Middle Sangoan levels at between 202-142 ka (152 $\pm 10 \mathrm{ka}$ [65]). Van Peer et al. [65] suggest that this site, along with Kalambo Falls, strengthens the case for identifying the long-debated Sangoan as a valid taxonomic entity for the early MSA, with a geographical distribution extending far beyond the Congo basin. Compared to other "transitional" sites, it is perhaps significantly younger at between 242 and $142 \mathrm{ka}$, when classical MSA assemblages already occur in eastern and southern Africa. Van Peer et al. [65] state that the OSL ages below the lowest Sangoan layer and above the Acheulian layers were quite scattered. Without publication of this data it is impossible to evaluate the reliability of these ages. In certain circumstances with high background radiation concentrations these ages could be considered as minimum age estimates due to saturation of the OSL signal. In the lowest Sangoan assemblage, hand axes are actually absent, but it also has few flake tools and has been designated primarily on the basis of heavy duty tools such as core axes [65]. The only hand axes that do occur come are two from the Middle Sangoan levels. Rots and Van Peer [118] suggest this is a reflection of core-axe manufacture at the site. The core axes are suggested to have been hafted and represent a complex behavioural system suggestive of economic specialization [118]. Rots and Van Peer [118] suggest that the Sangoan should be maintained as a taxonomic unit and that it represents the earliest stage of the MSA, at least in that part of Africa. Other Sangoan sites in eastern Africa include those from the Lake Eyasi Beds in Tanzania which has an interpreted age of $>132 \pm 7 \mathrm{ka}$ based on uranium series ages from bones within the Mumba Rockshelter [119]. This age should be taken as a minimum age estimate and its stratigraphic correlation to the Sangoan bearing deposits is also likely questionable. Younger simplistic flake industries from the Northeast Bay of Lake Eyasi, which have also been attributed to the MSA and are dated to between 132 and $82 \mathrm{ka}$ although high thorium concentrations in the samples make the dating less than ideal [24]. These MSA artefacts are interestingly associated with an archaic Homo sapiens skull despite this young age.

\section{Earlier MSA Sites in Southern Africa}

Until recently, there was little evidence for the period between these Acheulian deposits and the occurrence of widespread MSA bearing caves along the coast of South Africa in the last $120 \mathrm{ka}$ [120]. The oldest MSA sites were Florisbad $(279 \pm 47 \mathrm{ka}[12,19])$, Klasies River Mouth (<120 ka [120]; 115-107 ka; [20]), and Border Cave [19]. Florisbad is associated with (H. helmei) and the other two sites with modern humans. More recently a series of new potentially early MSA sites have been identified in southern Africa. Including sites in South Africa, Zambia, and Namibia. The new river terrace site of Cafema, along the Lower Cunene River on the border of Namibia and Angola is noticeable in being in an area where little information was previously known [121]. However, current dating of the site is based on sand layers beneath the archaeology which provides a maximum age estimate of $\sim 220 \mathrm{ka}$ and as such the MSA could be much younger [121].

5.1. Pinnacle Point. Along the coast the lack of older deposits was hypothesised to be due to the fact that the last interglacial high sea level stand at $\sim 125 \mathrm{ka}$ (MIS 5) would have eroded out any earlier deposits (e.g., MIS 6) from these coastal cave sites, or they would have occurred on the now submerged coastal platform [122]. However, there was little evidence of this. Recent confirmation of this has come in the form of MSA deposits from the LC-MSA lower horizon of Cave $13 \mathrm{~B}$ at Pinnacle Point at $\sim 174-153 \mathrm{ka}$ [18]. These have survived as remnants along the wall of the cave and were not washed out by high sea levels due to the caves elevation and due to the cementation of the deposits by speleothem. Blades, points, and Levallois flakes all occur in the LC-MSA Lower along with frequent bladlets [18]. Blades are more common than points, which have similarities to the sequence described from the undated levels at the Cave of Hearths [123]. Schoville [124] suggests that edge damage is consistent with the use of points as knives rather than projectile points and as a whole the assemblage lacks significant retouch or formal tools. Brown et al. [125] also suggest the presence of heat-treated silcrete lithics in these deposits although they are more numerous during the LC-MSA Middle deposits between 130 and $120 \mathrm{ka}$ [126]. Pinnacle Point has also yielded humans remains [17]; however, their age is uncertain given that they were found out of context. An age of between 170 and $91 \mathrm{ka}$ is a broad estimate for the age of the fossils based on the age of the deposits at the site [126]. 
5.2. Border Cave. All the H. sapiens fossil remains from Border Cave (BC1-5) are older than the Howieson's Poortlayers and are likely older than $\sim 65 \mathrm{ka}$ based on the dating of the Howieson's Poort at numerous sites across S. Africa $[19,50]$. This is supported by the direct dating of the youngest BC5 fossil to between 79 and $69 \mathrm{ka}$ using ESR [19, 127]. The ESR dates further suggest that the BC3 burial is around 84-72 ka [19]. Perforated shells similar to the ones found in the burial are known from Blombos and Sibudu Caves in association with the Still Bay around 76-69 ka [50] and in North Africa with the Aterian around $\sim 82 \mathrm{ka}[128]$. The BC1-2 remains and the oldest MSA lie somewhere between 179 and $80 \mathrm{ka}$ depending on their provenience, while potentially older and relatively unexcavated MSA layer, 6BS, is perhaps as old as 238-217 ka [19]. As at Sterkfontein (see above), the reliability of the ESR ages at Border Cave are high due to the very low levels of uranium in the samples, which simplifies uptake history modelling, as well as their broad agreement with the radiocarbon ages on younger deposits (ESR ages are very slightly younger than the C14 ages) and amino acid age estimates $[19,129,130]$.

5.3. Cave of Hearths. The Cave of Hearths has often been considered to be comparable to the older deposits at Border Cave, being termed part of the Pietersberg Industry, also suggested to occur at Wonderwerk Cave [61]. Unfortunately, the Cave of Hearths remains undated radiometrically. Sinclair [131] notes that hominins practiced PCTs to make blades and convergent points with a small number of these flakes being modified further without clear evidence that they were being retouched to a clear design. Sinclair [131] suggests that this minimal sense of patterning in the MSA is consistent throughout the sequence. However, in the earliest levels, blades generally tend to be much longer, while in the younger layers, retouched points tend to be more numerous. In both cases these pieces are minimal. Beaumont and Vogel [47] suggest that bed 4 here represents a Fauresmith Industry due to the occurrence of two possible LCTs from this layer. However, McNabb [103] and Sinclair [131] note no evidence for a Fauresmith like assemblage at the site.

5.4. Florisbad. Florisbad contains a number of MSA layer sand has also yielded remains of Homo helmei, dated by ESR to $259 \pm 35 \mathrm{ka}(294-225 \mathrm{ka}[12,19])$. The oldest MSA bearing layers are Units N-P (Peat 1 and Brown Sand) which range in age between 327 and $208 \mathrm{ka}$ based on a combination of ESR and OSL [19]. The ESR and OSL correlate quite well although with large error ranges (ESR: $259 \pm 35 \mathrm{ka} / \mathrm{OSL} 279$ $\pm 47 \mathrm{ka}$ and $281 \pm 73 \mathrm{ka}$ [19]). However, there is a significant scatter in ESR ages for some layers and inversion of ages for both ESR and OSL ages. However, the ESR ages are not completely inverted as stated by Millard [116] the depth scale is inverted in the Grün et al. [12] publication. Grün et al. [12] state that this is due to the complex history of the spring formation and intermixing of both fossils and older and younger quartz. As the OSL dating was multigrain rather than the more modern single-grain dating method this is quite likely. Grün [19] states that the main error is the uncertainty in the reconstruction of the radioactive environ- ment. Most layers have a very low density of stone tools (15176 artefacts), the exceptions being Unit F (1654 artefacts), dated to $121 \pm 6 \mathrm{ka}(127-115 \mathrm{ka})$ using ESR and $133 \pm 31 \mathrm{ka}$ (164-102 ka) and $128 \pm 22 \mathrm{ka}(150-106 \mathrm{ka})$ using OSL [13]. As such, the MSA occupation is most likely dated to the beginning of MIS 5. This deposits has a large assemblage of expedient, lightly retouched MSA tool types and utilized flakes with few formal tools and little variability [13].

Florisbad Unit $\mathrm{M}$, has a relatively substantial occupation given the size of the trench at this depth (120 artefacts) and is dated by OSL to $157 \pm 32 \mathrm{ka}(189-125 \mathrm{ka}[13,19])$. As such, this is an MIS 6 occupation, a period when some researchers believe early modern humans were only located along the coast of South Africa [132]. The Florisbad dates and perhaps also those from Border Cave suggest this was not entirely the case, unless these MSA assemblages are being made by remnant but soon to be extinct populations of archaic modern humans. Kuman et al. [13] note that unit $\mathrm{M}$ has a proportion of heavily retouched artefacts, mostly sidescrapers and a number of retouched points and convergent flake blades. The oldest MSA artefacts are dated to between 327 and $208 \mathrm{ka}$, and Kuman et al. [13] suggests that the oldest MSA is on a wider range of raw materials and is generally quite informal when compared to the younger material. There is less emphasis on prepared core techniques, and there are no heavily retouched pieces and only one point. However, this is with the caveats that this is only the case if the material excavated by Meiring (see [133]; 75 artefacts plus Kuman et al. [13]) were well provenance and representative. Given the formation of the site the hominin skull likely dates to MIS 7 ( 145$190 \mathrm{ka}$ ). An upper age range for the MSA at Florisbad is probably the beginning of MIS $8 \sim 310 \mathrm{ka}$. The age of the oldest MSA and the hominin remains from Florisbad are therefore, roughly the same age estimates for the oldest MSA in the Kapthurin and Gademotta Formations (see [106, 113, 115] 280-250 ka) and again older than the anatomically modern human remains from Omo and Herto 198-147 ka [15, 16].

5.5. CoHK. A number of new sites have also been excavated in the CoHK. Lincoln Cave has yielded an MSA assemblage dated by uranium series to somewhere between $278-107 \mathrm{ka}$ $(252.6 \pm 35.6$ and $115.3 \pm 7.7 \mathrm{ka}$; [134]). Reynolds et al. [134] note that Acheulian like cores occur in Lincoln cave and explain their occurrence as mixing from Member $5 c$ rather than the late occurrence of these core types. Contemporary MSA bearing deposits (post-Member 6; [135]) from the main quarry at Sterkfontein have also been dated to between 294-210 ka using ESR (252 $\pm 42 \mathrm{ka}[74])$. An archaic Homo sapiens fossil has been recovered from here [135]. Significant mixing has taken place and Homo ergaster fossils have also been recovered from Lincoln Cave [134]. Given that the postMember 6 deposits are seemingly continuous with Lincoln Cave [135] these ESR ages may suggest that the Lincoln Cave MSA is closer in age to $278 \mathrm{ka}$ than $115 \mathrm{ka}$. Taken together, this suggests that MSA tools are at least as old as $210 \mathrm{ka}$ in the Sterkfontein area. Younger MSA deposits have also been recovered from Member 4 deposits at Swartkrans $(<110.0 \pm$ $2.0 \mathrm{ka}[136])$ and between $90.3-61.6 \mathrm{ka}(62.9 \pm 1.3 \mathrm{ka}$ and $88.7 \pm 1.6 \mathrm{ka}[137]$ ) at Plovers Lake (both dated by uranium 
series on speleothem). A direct single isochron ESR date of $81.2-70.0 \mathrm{ka}(75.6 \pm 5.6 \mathrm{ka})$ for the Plovers Lake artefact horizon correlates well with the U-Th age [130]. This data, along with that presented by Herries et al. [67] and Herries and Shaw [79] further illustrates the robust nature of the ESR dating of the CoHK sites with ESR correlating well with other geochronological methods over a time range of $2.6 \mathrm{Ma}$ to $\sim 80 \mathrm{ka}$. As Grün [19] notes, these sites are ideal for ESR due to their low uranium content. Such comparisons make it highly likely that ESR ages for the ESA bearing Sterkfontein Member 5 deposits are also reliable when discrepancies in the geological context are taken into account $[75,85]$. These new dates for the CoHK sites indicate a rich MSA heritage that has until recently been overlooked due to a predominant interest in the early hominin and early stone age bearing layers of these sites. This recent work suggests that MSA deposits may occur in the CoHK between $\sim 250$ and $\sim 60$ ka with the oldest being as old as those from East Africa.

5.6. Twin Rivers (Zambia). Barham et al. [138] describe early MSA technology from block $\mathrm{A}$, and $\mathrm{F}$ at Twin Rivers in Zambia. In block A a flowstone at the base of the deposit as well as a piece within the deposits has been dated to $>400 \mathrm{ka}$ and is an upper age limit for the deposit. However, Barham et al. [138] suggest a hiatus occurs before deposition of the slurry flow which has seemingly eroded parts of the basal flowstone into the deposit. The oldest MSA deposits from Twin Rivers (Block A) are suggested to date to between $\sim 266$ and $\sim 172 \mathrm{ka}$, while those from $\mathrm{F}$ block are suggested to date to between $\sim 200$ and $\sim 140 \mathrm{ka}$ [138]. This A block assemblage includes backed tools that suggest early evidence for composite tool technology as well as bifacial projectile points and tanged points. Unifacial points were not recovered during the 1999 excavations but occurred in very low frequency during Clark's excavations during the 1950s [138]. Such points do occur in the deposits younger than $\sim 100 \mathrm{ka}$ [138]. The bifacial points include lanceolates characteristic of the early Lupemban and flaking occurred using both an anvil technique and radial and prepared core technique [138]. Twin Rivers stands as some of the earliest potential evidence for the MSA in southern Africa and particularly the definitive use of ochre [139]. However, many researchers are sceptical over the association of the flowstone to the MSA bearing deposits.

In many instances, flowstone is sampled from the wall or edges of a cave cavity without definitive evidence for its association to the archaeology. At Twin Rivers, for example, the flowstone does not occur as a continuous layer capping the MSA deposits but as remanents on the edge of the cavity. Therefore, the flowstone perhaps only provides a maximum age estimate ([138, Figure 10.15, 10.13]). The fact that younger speleothem dated to between 184-172 ka $(178 \pm 6 \mathrm{ka})$ and $141-137 \mathrm{ka}(139 \pm 2 \mathrm{ka})$ occurs under a speleothem dated to between $200-190 \mathrm{ka}(195 \pm 5 \mathrm{ka}$; 131) in block A. All TL dates from G block are younger than $117 \mathrm{ka}$ $(101 \pm 16 \mathrm{ka})$ and lend further suspicion to an extremely complicated stratigraphy and infill. The speleothem dates to between $266 \pm 6 \mathrm{ka}(272-260 \mathrm{ka})$ and $172 \pm 2 \mathrm{ka}(174-$ $170 \mathrm{ka})$ may also have been eroded out from earlier deposits when the MSA in-filled the cavity. Again younger speleothem samples occur with depth with the $172 \mathrm{ka}$ sample being deeper $(3.2 \mathrm{~m})$ than the $192 \pm 2 \mathrm{ka}$ sample at the top of A block at $2.2 \mathrm{~m}$. All the MSA in the top $1 \mathrm{~m}$ of A block is, therefore, younger than $174 \mathrm{ka}$, as the speleothem must have formed before it was eroded and incorporated into the breccia and so provides a maximum age. A TL age from over $4 \mathrm{~m}$ depth gave an age of $132 \pm 31 \mathrm{ka}$ and would suggest that all the deposits are younger than $163 \mathrm{ka}$, but the dose rate estimates for the deposits from which the sample came were not estimated, and a dose from higher in the sequence was used [138], making the date unreliable. However, a UTh sample with a date of $160 \pm 3 \mathrm{ka}$ also occurs at $2.4 \mathrm{~m}$ depth and is the youngest age from block A. This suggests that all the MSA in block A may in fact be younger than $163 \mathrm{ka}$. If the majority of speleothem represents material eroded into the deposit then the Lupemban from block A would be younger than $141 \mathrm{ka}$, significantly younger than the 266-170 ka cited by Barham et al. [138], the $>266 \mathrm{ka}$ or $>230 \mathrm{ka}$ age estimate that is often cited [140], or the $\sim 300 \mathrm{ka}$ age cited by Barham [141]. There is little evidence that the MSA deposits are older than $266 \mathrm{ka}$ except for a small deposit at the very bottom of the excavation, and this does not apply to the assemblage as a whole. The F block deposits are also potentially $<140 \mathrm{ka}$ based on the U-Th ages and G block is likely $<117 \mathrm{ka}$ based on TL ages. An age range of 141-48 ka could be estimated for the various MSA deposits at Twin Rivers based on the uncertainty of the provenience of the speleothem samples (Excavators need to be extremely careful when relating fragments of flowstone to wider archaeological deposits in caves due to their complex depositional history. All publications should show a clear photograph of the association of the speleothem to the deposit been dated or even micromorphological analysis across the contact. Often, dates are presented without any information regarding their reliability or context).

\section{Fauresmith and Sangoan Sites in Southern Africa}

Fauresmith sites have been noted at numerous sites on the Vaal River (e.g., Canteen Koppie, Nooitgedacht 2, Roseberry Plain 1, and Powers site), the Orange River, and the Seacow Valley as well as pan sites near Kimberley (Kathu Pan and Rooidam) and the cave site of Wondwerk Cave [140]. Almost all these occur in eastern-central south Africa, the exceptions being at and perhaps Bushman's rockshelter [142].

6.1. Kalambo Falls (Zambia). Clark [56] first described the Kalambo Falls site and identified a number of floors. Clarke [56] notes that it is the smaller chert tools (blades and unifacial points with faceted platforms and prepared cores) in addition to the larger hand axes and cleavers that give the Kalambo Falls assemblages, particularly floor 4, a Fauresmith flavor, and make it seemingly distinct from the industries in the Luangwa Valley. These floors were later termed archaeological horizons, but many are now not considered to be in situ accumulations but material redistributed by alluvial action [30]. The locality is extensively described in [30], and four main sites have been defined $[A-D]$. The 
lowest horizons have been defined as Upper to Terminal Acheulian in character and are referred to as the Bwalya Industry, and it has a very high percentage of LCTs (e.g., $67 \%$ of the shaped tools in one excavated horizon [30]). Many of the LCTs are small, lanceolate in shape, and could be argued to represent bifacial points evolving in the direction of the later Lupemban points. Small scrapers make up the majority of the light duty tools a few of which are convergent and resemble unifacial triangular points [30].

A series of Sangoan horizons follow that are referred to as the Chipeta Industry [30]. It has a much higher percentage of light duty tools, particularly scarpers, and it is suggested that this stage represents the beginning of the MSA and disappearance of Acheulian LCTs [30]. There is a trend towards more specialised flake forms, with blades [30]. The characteristic large tool is the core axe, which does occur in the lower Acheulian horizons but is in much greater number in the Sangoan levels. Clark [30] states "that the Chipeta Industry, though in some ways transitional, is the initial stages in the MSA trend to increased specialisation". While lanceolates are absent in the Kalambo Falls Sangoan, Clark [30] notes that they do occur in other Sangoan assemblages. These are also undated and may be younger than that from Kalambo Falls. Lanceolate bifaces are the characteristic tool of the Lupemban levels of the MSA [30] along with an increase in lighter duty tools such as retouched unifacial points and blades. Potentially, utilised wood also come from the Acheulian and Sangoan levels and consist of possible clubs and pointed stakes and tools [30]. Sheppard and Kleindienst [143] concluded that there is little change, at Kalambo Falls, in the basic techniques of blank production or the attributes of the blanks produced from the earliest Acheulian layers to the later MSA layers. The only marked change to occur is the loss of LCTs (hand axes and cleavers) and their replacement by heavy-duty forms of core axes and picks. While lanceolates are absent in the Kalambo Falls Sangoan, some of the LCTS from the Acheulian layers have a similar lanceolate character that suggests some continuity between these earliest levels and the Lupemban. The intermediate Sangoan may represent an industry related to a particular climatic shift in the region, perhaps related to a warmer, more forested interglacial.

A range of radiocarbon ages exist for these early levels (60.3-32.6 ka BP [144]), but they are considered to be infinite age estimates [30]. This was followed by an amino-acid racemization age on wood from the Acheulian levels that suggested an age of $\sim 110 \mathrm{ka}$ [143]. A series of uranium series ages were then undertaken on wood, but because of the open system nature of the samples, they should be considered as minimum age estimates. The Acheulian layers were dated to $182 \pm 16 \mathrm{ka}$ and $182 \pm 10 \mathrm{ka}(198-166 \mathrm{ka})$ and the Sangoan levels to $76 \pm 10 \mathrm{ka}(85-65 \mathrm{ka})$. Hopefully, OSL dates will soon be forthcoming for at least the younger MSA (Lupemban) deposits at Kalambo Falls [145].

6.2. Bundu Farm. Peter Beaumont excavated a number of sites in the Northern Cape Province throughout the 1970s and 1980s and it is these sites that now appear to hold the key to understanding the transition between the Acheulian and the MSA in the region. Kiberd [146] recently described new excavations at the site of Bundu Farm in Northern Cape. The site has yielded only one LBCT from layer G6 but Kiberd [146] defines layers 4-6 as a terminal Acheulian or transitional ESA/MSA industry (i.e., Fauremsith). Layer G4 was dated by Kiberd [146] to $145.7 \pm 16.0 \mathrm{Ka}$, providing a minimum age estimate for the G6 layer of $>129.7 \mathrm{ka}$. Unprovenienced teeth from the site gave ESR age estimates of between 394 and $144 \mathrm{ka}$. Based on the occurrence and absence of fauna in layers of the site, Kiberd [146] suggests that this fauna most likely came from layers G4 and G5. This suggests that the G6 horizon containing the LCTs is dated to $>\sim 300-400 \mathrm{ka}$ based on a linear uptake model (this model is the one that gives consistent ages for the CoHK sites) and $\sim 200$ ka based on an early uptake model. Prepared cores occur in all layers but are slightly more abundant in the younger layers that are $<161 \mathrm{ka}$. In contrast, flake blades (this includes points, which are often referred to as convergent flake blades in South Africa) are generally more abundant in the oldest layer (G6), which also contains the one LBCT. Worked bifacial points also occur throughout the sequence. Overall, the sequence shows the occurrence of Levallois technology, blades, and points and in the oldest layer (G6) a single LBCT. Overall, the Bundu farm sequence appears to contain all the components of the MSA in layers that are most likely dated to sometime between 400 and $200 \mathrm{ka}$. Brink (pers. Comm. In Kiberd [146]) notes that the Connochaetes gnou fossils are of a similar size to those from Florisbad (294$225 \mathrm{ka} ;[19])$ and that the fossils reflect a period of increased rainfall. Based on the early uptake model for the ESR ages the oldest deposits G4-6 perhaps dates to roughly MIS 7 at $\sim 240-190 \mathrm{ka}$. If the linear uptake model is correct (as it appears to be for many sites in South Africa), the oldest layers likely date to MIS9 between 340-310 ka.

6.3. Wonderwerk Cave. Beaumont and Vogel [47] describe the results of excavations at Wonderwerk Cave. It has a sequence of what are suggested to be almost continuous deposits dating back nearly 2 million years [47, 71]. Beaumont and Vogel [47] suggest that MSA assemblages are represented in Major Units (MU) 2 in excavations 2, 3, 5, 6 and 7 and Fauresmith assemblages in MU3-4 in excavations 1 and 2. In contrast, Chazan et al. [75] note that no Fauremsith like material is noted in their reanalysis of the excavation 1 material. The excavation 1 material is, therefore, entirely Acheulian in character, and its age has previously been discussed above. Chazan and Horwitz [147] further suggest that all material from excavation 6 is Fauresmith in character with the co-occurrence of "oversized blades", prepared core technology and LBCT in contrast to Beaumont and Vogel's [47] interpretation of these deposits as being MSA. Chazan and Horwitz [147] also note that in Excavation 6, there is no evidence for underlying earlier ESA deposits as are found in Excavation 1 at the front of the cave, the top of which dates to $<780 \mathrm{ka}$ [75]. A single U/Th date (U-576) on a fragment of stalagmite [147] recovered from within the Fauresmith deposits of Excavation 6 gave an age of 187 $\pm 8 \mathrm{ka}(195-179 \mathrm{ka})$ [47] and palaeomagnetism records a normal magnetic polarity [47]. Beaumont and Vogel [47] 
state that this is a "minimum age" estimate for the age of the deposit and that it dates the Fauresmith to between $<780$ and $>179 \mathrm{ka}$. In actual fact, if a fragment of speleothem occurs within a deposit it must have grown before the deposit was formed, not after it. As such, this is a maximum age estimate for the layer in which the speleothem fragment was found and suggests the Fauresmith assemblage is $<195 \mathrm{ka}$, making it only slightly older than the Pinnacle Point MSA at 170$160 \mathrm{ka}$ and perhaps similar to the LBCT assemblage from Herto. If the speleothem capped the underlying deposit, then it would indeed suggest that the deposit below this were older than $179 \mathrm{ka}$. However, Chazan and Horwitz [147] are not clear on the contextual issue of this sample, the age for which has come from the earlier publication by Beaumont and Vogel [47]. Beaumont and Vogel [47] state that items of calcite, mainly in the form of small $(\sim 5-20 \mathrm{~cm}$ high) stalagmites, were found sporadically in many strata. They do not elaborate on the in situ or ex situ context of the material other than if it is a stalagmite of a stalactite. As stated above, if a fragment of speleothem occurs ex situ within a deposit, that deposit must be younger than the age of the speleothem, as the speleothem must have formed before being incorporated. If, however, a speleothem caps a deposit by forming directly on it and is in situ, then the deposits under it are older than that speleothem and the deposits above it in theory younger. If the speleothem is a flowstone, then it may also represent a false floor under which younger deposits may have been deposited. As previously noted, it is very important to understand and state the relationship of speleothems to the deposits and archaeology being dated and present clear evidence of this in publications.

The other ages for Fauresmith layers at Wonderwerk come from the top of stratum 3 in excavation 2 and give ages of between 315 and $247 \mathrm{ka}$. As these are soda straws that fell into the deposit after deposition of the Fauremsith deposits, they provide little chronological evidence for the age of the majority of the deposit other than suggesting that the layers in which the straws were found are younger than $247 \mathrm{ka}$. It does not, as Beaumont and Vogel [47] suggest necessarily mean that the Fauremsith layers date back to between 286 and $276 \mathrm{ka}$. A stalagmite in the top part of the MSA layers in excavation 2 had a basal age of 234-206 ka and may suggest that the MSA in this area is greater than $206 \mathrm{ka}$. However, the exact relationship of the stalagmite to the deposits is again not stated. It could simply have been incorporated into the deposits from elsewhere. There appears to be some evidence for the movement of material by water at the site which was once an active cave resurgence. This can be seen by the mixed nature of artefacts in the rear mostly in-filled tunnel and the eroded surface in many sections which slope back towards the rear of the cave. Moreover, a stalagmite that is seemingly lower in the section is dated to between 182 and $154 \mathrm{ka}$. This inversion of ages in the same excavation does not suggest the speleothems are in situ and would suggest that all of the MSA deposits are in fact younger than $182 \mathrm{ka}$. Until a better description of context is given for these samples all age assessments using, the data of Beaumont and Vogel [47] should be regarded with extreme caution. Many of the speleothems from the top of the MSA excavations in different trenches date to between 100 and $68 \mathrm{ka}$ and without a context for the samples the deposits could in theory be not much older than that age or even in theory younger. Based on this re-analysis, there appears to be little current evidence for Fauresmith deposits older than 300-200 ka.

6.4. Kathu Pan. Previous dating of the site was based on elephant fossils that were more evolved than those from Olduvai Bed IV [62]. This simply gave the site an age of $<1.07 \mathrm{Ma}$ or $<780 \mathrm{ka}$ based on the interpretation of the palaeomagnetic data [6]. At Kathu Pan, the MSA layers fall in the time range between 336 and $254 \mathrm{ka}(291 \pm 45 \mathrm{ka}$; [148], perhaps during MIS9 (340-310 ka). The layer 4a Fauresmith assemblage at Kathu Pan contains Levallois cores, retouched points, blades and LCBTs and has been dated, to somewhere between 511 and $435 \mathrm{ka}$ based on a combination of OSL (464 $\pm 47 \mathrm{ka})$ and ESR $(542+107 /-140 \mathrm{ka})$ [148]. Porat et al. [148] suggest that the OSL age may represent a minimum age estimate. If so, the layer would date to between 682 and $435 \mathrm{ka}$ (based on ESR alone). An MIS13 age (540-470 ka) might be a good estimate based on this data but certainly older than $417 \mathrm{ka}$. This suggests that all the tool forms found in the MSA are already in place by at least $417 \mathrm{ka}$. The retouched points have facetted platforms and are in stark contrast to early MSA assemblages that are suggested to lack formal tools and retouched points [148]. Porat et al. [148] note that the extreme lateral convexity of the lithics distinguishes them from the norm for the Levallois method, despite the fact that they typologically and technologically fit within the Levallois. The age of the Acheulian $4 \mathrm{~b}$ layers has not been determined other than being older than $4 \mathrm{a}$. Porat et al. [148] note that LCTs in the Fauremsith horizons are made on a wide range of raw materials and are crude and irregular, while those from the Acheulian are exclusively made on banded ironstone and are symmetrical and refined. This may reflect the hominins developing new raw materials for LBCT manufacture during the Fauresmith as part of experimentation of new methods of stone tool manufacture. The occurrence of a Fauresmith industry at Kathu Pan, so close to Wonderwerk Cave, dated to $>417 \mathrm{ka}$ may lend weight to the Fauresmith at Wonderwerk also being in this time range or at least older than $182 \mathrm{ka}$ as suggested by Chazan and Horwitz [147] unless it occurred for over $200 \mathrm{ka}$ in the region and was being produced contemporarily with the MSA.

6.5. Mapangubwe. Kuman et al. [74] describe a series of sites (Keratic Koppie, Hackthorne, and Kudu Koppie) from the Mapungubwe National Park (formerly Vhembe Dongola NP) in northern South Africa on the border with Botswana and Zimbabwe. Kuman et al. [74] suggest the site represents a Charaman like industry as described from Zimbabwe, which itself is perhaps a version of the Sangoan. These two industries were grouped together into Clark's First Intermediate Period along with the Fauresmith [28]. The sites have tools that are again characteristic of the Acheulian and the MSA. Although they show marked typological differences, the parallels between the Sangoan and the Fauresmith are striking. Kuman et al. [74] suggest that after $200 \mathrm{ka}$ classic MSA technology occurs that is well 
developed, yet this does not reflect a change so much in the actual technology as a shift toward a lighter, more mobile toolkit which incorporates hafting. Wilkins et al. [149] note that the prepared core reduction strategies at Kudu Koppie suggest that both the late ESA and MSA toolmakers employed the Levallois Volumetric Concept, but they often exploited a nodule's natural convexities and form. The MSA toolmakers use a greater variety of prepared core methods and more intensively exploited cryptocrystalline and microcrystalline nodules, the scarcity of which may have resulted in a more "formalized" application of the Levallois Volumetric Concept. Kempson [150] suggests that the Hackthorne site may represent mixing of ESA and MSA deposits, while Keratic Koppie preserves an assemblage with a mixture of Acheulian and MSA components. Kempson [150] arguesd the assemblage is a post-Acheulian industry with a major component of woodworking tools, suggestive of the Sangoan Industrial Complex. Davies [64] and Kuman [66] also suggest the occurrence of Sangoan-like tools along the KwaZulu-Natal coast including coastal dunes near Port Edward, which if confirmed would truly throw out the idea that these are environmentally specific or regional entities. This is close to the site of Amanzi Springs which Deacon $[73,151]$ suggested might be later Acheulian.

6.6. Rooidam. The alluvial sites of Rooidam 1 and 2 were excavated by Fock [152]. Rooidam 1 contained a rich Stratum 9, which sits $3.9 \mathrm{~m}$ below the surface and yielded $90 \%$ of the 19,000 artefacts recovered from the site $[47,70$, 152]. Previously, the occurrence of small hand axes as well as a small amount of cleavers, blades and convergent points suggested this was a Fauresmith layer [70]. Beaumont and Vogel [47] later assigned this layer to the final Acheulian, stating that while prepared cores and blades were present, there were no convincing Levallois points. Here, Beaumont and Vogel [47] suggest that the late Acheulian can be distinguished on the basis of true blades and that Levallois points distinguish the Fauresmith. Here, the Fauremsith is reduced to an MSA assemblage that simply contains LCT. The upper MSA levels were also reclassified as Fauremsith, which also occurs at Rooidam 2. Szabo and Butzer [153] conducted U-Th dates on two calcretes sandwiched between the late Acheulian and Fauyremsith occupations and overlying the main stratum 9 occupation. Szabo and Butzer's [153] unit C correlates with Unit 9 of Beaumont [47, 70]. The U-Th ages are inverted for the sequence. The Unit $\mathrm{C}$ deposit of Szabo and Butzer [153] covering stratum 9 gave an age of $108+40 /-20 \mathrm{ka}$ (148-88 ka). The stratigraphically higher unit G gave an age of $174 \pm 35 \mathrm{ka}(209-139 \mathrm{ka})$. Szabo and Butzer [153] argue that the younger lower age is due to the open system nature of the system in Unit $\mathrm{C}$ and recrystallization. They state that recrystallization does not appear to have occurred in unit $\mathrm{G}$ and so the age is accurate for that unit. It seems likely that both ages are minimum age estimates due to the open nature of the system, and so, the age of the stratum 9 late Acheulian depositsat the site can only be said to be older than $139 \mathrm{ka}$. The upper Fauresmith deposits in theory date to less than $209 \mathrm{ka}$ and might suggest that the Fauresmith occurs relatively late at the site; however, if recrystalisation had also effected the lower sample to any degree, then these deposits might also be significantly older than this.

6.7. Taung. Kuman [154] describes a series of undated sites (DB3 and 4) near Taung where LCTs are associated with convergent points and prepared core technology and also with a higher representation of end struck rather than side struck flakes, diagnostic features of the Fauresmith. At DB3 Kuman [154] notes the occurrence of Levallois and Victoria West cores in the same context. Hence, despite the dominance of simple flaking features, core types, faceted platforms and dorsal scar patterns together show a range of relatively advanced flaking techniques that are seen in the assumingly later MSA of the region [154]. At DB3, the majority of LCT are side struck, while most small tools are end struck, which is out of character for LCT of Fauresmith type as described by Goodwin [32]. This appears to show the very mixed character of the assemblage. The DB3 Acheulian assemblage contains three types of flaking technique (radial, convergent, and parallel opposed), which are documented more consistently in the ensuing Middle Palaeolithic and MSA [154].

6.8. Bushman's Rockshelter. Bushman's Rockshelter was excavated by Louw [142] who describes a number of LCTs or LCT-like stone tools from layer 41 . This has an uncalibrated C14 age of 47.5 BP [155] and is no doubt an infinite age. Louw [142] suggests that the hand axes may have been picked up by MSA people and reused, but it is also possible that this is a transitional industry, perhaps the Fauresmith, as the deposits do not seem to have Sangoan elements like the Limpopo sites. If so, then this would suggest a greater regional spread of the Fauresmith, but the deposit is as yet undated.

\section{Discussion and Conclusions}

As outlined in the opening discussion, there are a number of theories concerning the terminology of the ESA to MSA transition and it is likely far from a simple transition that occured at exactly the same time or the same way in different areas of Africa. The age of all the sites is outlined in Table 1. The sites of the Kapthurin and Gademotta Formation in eastern Africa indicate that the MSA in its classical sense occurs at roughly the same time between 300 and $250 \mathrm{ka}$. The Kathu Pan MSA at 336-254 ka is potentially older and suggests the earliest MSA occurs synchronously in eastern and southern Africa. Further potential evidence for this comes from Florisbad and Sterkfontein-Lincoln Cave sometime between 300 and $200 \mathrm{ka}$. The sites of the Kapthurin Formation also indicate that many characteristic elements of the MSA occur alongside elements of the ESA including LCTs from roughly 500 to $250 \mathrm{ka}$. These have been termed MSA, Sangoan, Fauresmith, and Acheulian depending on the groups of tools found at different sites and has been used to suggest independent evolution of all the elements (points, Levallois, etc.) that come together to form the MSA as an entity and in essence augments previous Acheulian technology [22]. Blades come into use first around 545-509 ka, followed by points, large prepared cores, and then centripetal 
TABLe 1: Age ranges for Acheulian, Fauresmith. Sangoan, and early MSA sites mentioned in the text.

\begin{tabular}{|c|c|c|c|c|c|c|c|c|}
\hline Country & Locality & Site/layers & $\begin{array}{l}\text { Dating } \\
\text { methods }\end{array}$ & Upper age & Lower age & $\begin{array}{l}\text { Best age } \\
\text { estimate }\end{array}$ & Industry & $\begin{array}{l}\text { Hominin } \\
\text { association }\end{array}$ \\
\hline Kenya & $\begin{array}{l}\text { Nachukui } \\
\text { Formation, } \\
\text { West Turkana }\end{array}$ & KS4 & $\mathrm{Ar}-\mathrm{Ar}$ & & $>1.65 \mathrm{Ma}$ & $\sim 1.65 \mathrm{Ma}$ & Acheulian & \\
\hline Ethiopia & Konso Gardula & KGA & $\mathrm{Ar}-\mathrm{Ar}$ & $1.69 \mathrm{Ma}$ & $1.41 \mathrm{Ma}$ & $\sim 1.5 \mathrm{Ma}$ & Acheulian & \\
\hline Tanzania & Olduvai Gorge & Upper Bed II & $\begin{array}{c}\text { K-Ar- } \\
\text { Ar/Palaeomag. }\end{array}$ & $1.53 \mathrm{Ma}$ & $1.27 \mathrm{Ma}$ & $1.5-1.3 \mathrm{Ma}$ & Acheulian & \\
\hline S. Africa & $\begin{array}{l}\text { Reitpuits } \\
\text { Formation } \\
\text { [23], Vaal River }\end{array}$ & CBD & Cosmogenics & $2.08 \mathrm{Ma}$ & $1.08 \mathrm{Ma}$ & $1.4-1.2 \mathrm{Ma}$ & Acheulian & \\
\hline S. Africa & Canteen Kopjie & $\begin{array}{l}\text { Stratum 2b } \\
\text { lower }\end{array}$ & Cosmogenics & $1.61 \mathrm{Ma}$ & $0.82 \mathrm{Ma}$ & $\begin{array}{c}<1.6- \\
>0.8 \mathrm{Ma}\end{array}$ & Acheulian? & \\
\hline S. Africa & $\begin{array}{l}\text { Wondwerwerk } \\
\text { Cave }\end{array}$ & Excavation 1 & Pmag. & $1.78 \mathrm{Ma}$ & $0.78 \mathrm{Ma}$ & $\begin{array}{c}<1.6- \\
>1.1 \mathrm{Ma}\end{array}$ & Acheulian & \\
\hline S. Africa & Swartkrans & Member 2 & $\begin{array}{c}\text { Fauna/U-Pb } \\
\text { [bone] }\end{array}$ & $1.65 \mathrm{Ma}$ & $1.07 \mathrm{Ma}$ & $1.6-1.1 \mathrm{Ma}$ & Acheulian & H. ergaster \\
\hline S. Africa & Sterkfontein & Member 5c & Pmag/ESR & $1.39 \mathrm{Ma}$ & $0.82 \mathrm{Ma}$ & $1.4-1.1 \mathrm{Ma}$ & Acheulian & H. ergaster \\
\hline S. Africa & Cornelia & Uitzoek & Pmag/fauna & $1.07 \mathrm{Ma}$ & $0.78 \mathrm{Ma}$ & $1.1-0.8 \mathrm{Ma}$ & Acheulian & early Homo \\
\hline S. Africa & Elandsfontein & all & Pmag/Fauna & $1.07 \mathrm{Ma}$ & $0.78 \mathrm{Ma}$ & $1.1-0.8 \mathrm{Ma}$ & Acheulian & $\begin{array}{l}\text { H. erectus } / H . \\
\text { rhodesiensis }\end{array}$ \\
\hline S. Africa & Swartkrans & Member 3 & $\begin{array}{c}\text { Fauna/U-Pb } \\
\text { [bone] }\end{array}$ & $1.04 \mathrm{Ma}$ & $0.62 \mathrm{Ma}$ & $1.0-0.6 \mathrm{Ma}$ & Acheulian & early Homo \\
\hline S. Africa & Gladysvale & internal & P-mag/ESR & $<990 \mathrm{ka}$ & $>780 \mathrm{ka}$ & $\sim 800 \mathrm{ka}$ & Acheulian & \\
\hline S. Africa & $\begin{array}{l}\text { Cave of } \\
\text { Hearths }\end{array}$ & Bed 1-3 & P-Mag & $<780 \mathrm{ka}$ & $400 \mathrm{ka}$ & $670-560 \mathrm{ka}$ & Acheulian & H. rhodesiensis \\
\hline S. Africa & Kathu Pan & STR4a & ESR/OSL & $647 \mathrm{ka}$ & $435 \mathrm{ka}$ & $540-470 \mathrm{ka}$ & Fauresmith & \\
\hline Kenya & $\begin{array}{l}\text { Wethwerill's } \\
\text { and } \\
\text { Cartwright's } \\
\text { sites }\end{array}$ & & $\mathrm{K}-\mathrm{Ar}$ & $<557 \mathrm{ka}$ & $>440 \mathrm{ka}$ & $?$ & $\begin{array}{l}\text { Pseudo- } \\
\text { Stillbay }\end{array}$ & \\
\hline Kenya & $\begin{array}{l}\text { Kapthurin } \\
\text { Formation }\end{array}$ & K3 & Ar-Ar & $548 \mathrm{ka}$ & $500 \mathrm{ka}$ & $548-500 \mathrm{ka}$ & Acheulian & \\
\hline Kenya & $\begin{array}{l}\text { Kapthurin } \\
\text { Formation }\end{array}$ & K4 & Ar-Ar & $<518 \mathrm{ka}$ & $>272 \mathrm{ka}$ & $<518 \mathrm{ka}$ & $\begin{array}{l}\text { Acheulian } \\
\text { with points }\end{array}$ & \\
\hline Kenya & $\begin{array}{l}\text { Kapthurin } \\
\text { Formation }\end{array}$ & $\begin{array}{l}\text { K4 (Rorop } \\
\text { Lingop) }\end{array}$ & $\mathrm{Ar}-\mathrm{Ar}$ & $<518 \mathrm{ka}$ & $>272 \mathrm{ka}$ & $>272 \mathrm{ka}$ & $\begin{array}{l}\text { Acheulian/MS } \\
\text { Fauresmith }\end{array}$ & A/Sangoan/ \\
\hline S. Africa & Bundu Farm & G4-6 & ESR/Fauna & $>394 \mathrm{ka}$ & $\sim 200 \mathrm{ka}$ & & Fauresmith & \\
\hline S. Africa & Rooidam 2 & Unit to $\mathrm{G}$ & U-Th & $?$ & $>154 \mathrm{ka}$ & $>154 \mathrm{ka}$ & Acheulian & \\
\hline Sudan & Sai Island & YG & OSL & $?$ & $>204 \mathrm{ka}$ & $>204 \mathrm{ka}$ & Acheulian & \\
\hline S. Africa & Rooidam 2 & Unit A-B & U-Th & $>154 \mathrm{ka}$ & $?$ & & Fauresmith & \\
\hline S. Africa & Kathu Pan & STR3 & OSL & $336 \mathrm{ka}$ & $254 \mathrm{ka}$ & $336-254 \mathrm{ka}$ & MSA & \\
\hline S. Africa & $\begin{array}{l}\text { Wonderwerk } \\
\text { Cave }\end{array}$ & Excavation 2, 6 & $\mathrm{U}-\mathrm{Th}$ & $315 \mathrm{ka}$ & $<195 \mathrm{ka}$ & $315-<195 \mathrm{ka}$ & Fauresmith & \\
\hline Kenya & $\begin{array}{l}\text { Kapthurin } \\
\text { Formation }\end{array}$ & Koimillot & stratigraphy & $<296 \mathrm{ka}$ & $<237 \mathrm{ka}$ & 250-200 ka & MSA & \\
\hline S. Africa & Florisbad & Peat 1 & ESR/OSL & $295 \mathrm{ka}$ & $225 \mathrm{ka}$ & $295-225 \mathrm{ka}$ & MSA & H. helmei \\
\hline S. Africa & Sterkfontein & M6/post M6 & ESR & $294 \mathrm{ka}$ & $210 \mathrm{ka}$ & 294-210 ka & MSA & $\begin{array}{l}\text { archaic } H . \\
\text { sapiens }\end{array}$ \\
\hline S. Africa & Lincoln Cave & south/north & U-Th & $278 \mathrm{ka}$ & $107 \mathrm{ka}$ & $278-107 \mathrm{ka}$ & MSA & H. ergaster? \\
\hline Ethiopia & $\begin{array}{l}\text { Gademotta } \\
\text { Formation }\end{array}$ & Type site Unit 9 & Ar-Ar & $?$ & $>272 \mathrm{ka}$ & $\sim 280 \mathrm{ka}$ & MSA & \\
\hline
\end{tabular}


TABle 1: Continued.

\begin{tabular}{|c|c|c|c|c|c|c|c|c|}
\hline Country & Locality & Site/layers & $\begin{array}{l}\text { Dating } \\
\text { methods }\end{array}$ & Upper age & Lower age & $\begin{array}{l}\text { Best age } \\
\text { estimate }\end{array}$ & Industry & $\begin{array}{l}\text { Hominin } \\
\text { association }\end{array}$ \\
\hline Ethiopia & $\begin{array}{l}\text { Gademotta } \\
\text { Formation }\end{array}$ & Kulkuletti & $\mathrm{Ar}-\mathrm{Ar}$ & $?$ & $>272 \mathrm{ka}$ & $\sim 280 \mathrm{ka}$ & MSA & \\
\hline Zambia & $\begin{array}{l}\text { Twin Rivers } \\
\text { (Zambia) }\end{array}$ & Block A & U-Th & $<266 \mathrm{ka}$ & $<132 \mathrm{ka}$ & $<132 \mathrm{ka}$ & $\begin{array}{c}\text { MSA } \\
\text { (Lupemban) }\end{array}$ & \\
\hline Ethiopia & $\begin{array}{l}\text { Gademotta } \\
\text { Formation }\end{array}$ & Unit 11 & $\mathrm{Ar}-\mathrm{Ar}$ & $<280 \mathrm{ka}$ & $>173 \mathrm{ka}$ & $280-173 \mathrm{ka}$ & MSA & \\
\hline Sudan & Sai Island & BLG/TLG/UG & OSL & $<243 \mathrm{ka}$ & $>142 \mathrm{ka}$ & $200-160 \mathrm{ka}$ & Sangoan & \\
\hline S. Africa & Border Cave & $6 \mathrm{BS}$ & ESR & $238 \mathrm{ka}$ & $217 \mathrm{ka}$ & $238-217 \mathrm{ka}$ & MSA & \\
\hline Zambia & Kalambo Falls & $\begin{array}{l}\text { Acheulian } \\
\text { Layers }\end{array}$ & U-Th/AAR & $>198 \mathrm{ka}$ & $>166 \mathrm{ka}$ & $>166 \mathrm{ka}$ & Acheulian & \\
\hline S. Africa & Twin Rivers & Block F & U-Th & $>195 \mathrm{ka}$ & $<140 \mathrm{ka}$ & $<140 \mathrm{ka}$ & $\begin{array}{c}\text { MSA } \\
\text { (Lupemban) }\end{array}$ & \\
\hline S. Africa & Border Cave & 5BS/5WA & ESR/AAR & $183 \mathrm{ka}$ & $141 \mathrm{ka}$ & $183-141 \mathrm{ka}$ & MSA & H. sapiens? \\
\hline S. Africa & $\begin{array}{l}\text { Wonderwerk } \\
\text { Cave }\end{array}$ & $\begin{array}{l}\text { Excavation 2, 3, } \\
5\end{array}$ & U-Th & $182 \mathrm{ka}$ & $118 \mathrm{ka}$ & $182-118 \mathrm{ka}$ & MSA & \\
\hline S. Africa & $\begin{array}{l}\text { Pinnacle Point } \\
13 \mathrm{~B}\end{array}$ & LC-MSA Lower & OSL & $174 \mathrm{ka}$ & $153 \mathrm{ka}$ & $\sim 164 \mathrm{ka}$ & MSA & H. sapiens? \\
\hline Ethiopia & $\begin{array}{l}\text { Bouri } \\
\text { Formation }\end{array}$ & $\begin{array}{l}\text { Upper Herto } \\
\text { Member }\end{array}$ & $\mathrm{Ar}-\mathrm{Ar}$ & $166 \mathrm{ka}$ & $147 \mathrm{ka}$ & $166-147$ & MSA & H. sapiens \\
\hline S. Africa & Pinnacle Point & DB Sand $4 b$ & OSL & $166 \mathrm{ka}$ & $152 \mathrm{ka}$ & $166-152 \mathrm{ka}$ & MSA & H. sapiens? \\
\hline S. Africa & Bundu farm & G2-3 & ESR/Fauna & $162 \mathrm{ka}$ & $130 \mathrm{ka}$ & $162-130 \mathrm{ka}$ & MSA & \\
\hline Sudan & Sai Island & Nile silts & OSL & $<162 \mathrm{ka}$ & $?$ & $<162 \mathrm{ka}$ & $\begin{array}{c}\text { Lupemban- } \\
\text { Like } \\
\text { MSA }\end{array}$ & \\
\hline Zambia & Kalambo Falls & Floor 4 & U-Th & $>85 \mathrm{ka}$ & $>65 \mathrm{ka}$ & $>65 \mathrm{ka}$ & Sangoan & \\
\hline S. Africa & $\begin{array}{l}\text { Pinnacle Point } \\
\text { 13B }\end{array}$ & $\begin{array}{l}\text { LC-MSA } \\
\text { Middle/Upper }\end{array}$ & OSL/U-Th & $130 \mathrm{ka}$ & $115 \mathrm{ka}$ & $130-115 \mathrm{ka}$ & MSA & H. sapiens? \\
\hline Kenya & $\begin{array}{l}\text { Central Rift } \\
\text { (Kapedo) }\end{array}$ & Kapedo Tuffs & $\mathrm{Ar}-\mathrm{Ar}$ & $135 \mathrm{ka}$ & $120 \mathrm{ka}$ & $135-120 \mathrm{ka}$ & MSA & \\
\hline Eritrea & Abdur & & & $132 \mathrm{ka}$ & $118 \mathrm{ka}$ & $125-118 \mathrm{ka}$ & $\begin{array}{l}\text { MSA with } \\
\text { LCTs }\end{array}$ & \\
\hline S. Africa & $\begin{array}{l}\text { Klasies River } \\
\text { Mouth }\end{array}$ & LBS & OSL & $120 \mathrm{ka}$ & $90 \mathrm{ka}$ & $120-90 \mathrm{ka}$ & MSA & H. sapiens \\
\hline S. Africa & Border Cave & 4WA & ESR/AAR & $122 \mathrm{ka}$ & $111 \mathrm{ka}$ & $122-111 \mathrm{ka}$ & MSA & H. sapiens \\
\hline S. Africa & Swartkrans & Member 4 & U-Th & $?$ & $<108 \mathrm{ka}$ & $<108 \mathrm{ka}$ & MSA & \\
\hline S. AfricA & Twin Rivers & Block G & $\mathrm{TL}$ & $<117 \mathrm{ka}$ & $48 \mathrm{ka}$ & $117-48 \mathrm{ka}$ & MSA & \\
\hline S. Africa & $\begin{array}{l}\text { Pinnacle Point } \\
13 \mathrm{~B}\end{array}$ & $\begin{array}{l}\text { Western } \\
\text { Excavation }\end{array}$ & OSL/U-Th & $114 \mathrm{ka}$ & $91 \mathrm{ka}$ & $114-91 \mathrm{ka}$ & MSA & H. sapiens? \\
\hline Kenya & Malewa Gorge & Malewa Gorge & $\mathrm{Ar}-\mathrm{Ar}$ & ? & $>86 \mathrm{ka}$ & $\sim 118-86 \mathrm{ka}$ & MSA & \\
\hline
\end{tabular}

Levallois cores and flakes all the while occurring with LCTs. It is not until 250-200 ka that convergent Levallois flakes and cores occur in the absence of LCTs that the MSA is seen to start. Of course, LCTs may occur much later $(<160 \mathrm{ka})$ in some contexts in Etirea and Ethiopia. Interestingly, the $>272 \mathrm{ka}$ MSA in the Gademotta Formation in Ethiopia seems not to be underlain by such transitional industries [22].

Potentially similar trends are seen at Kalambo Falls with a transition from the Acheulian, through the Sangoan and into the Lupemban-MSA, but this site remains unreliably dated. At Kalambo Falls, there seems to be a definite trend through time but with the Sangoan being more of a distinct entity, perhaps relating to a more forested, interglacial period. The only reliably dated Sangoan assemblage comes from Sai Island in the Sudan at sometime between 242$142 \mathrm{ka}$. This is contemporary with the early MSA assemblages in the Kapthurin and Gademotta Formation as well as several sites in southern Africa (Border Cave, Florisbad, and Sterkfontein-Lincoln Cave). At Kalambo Falls, the Sangoan directly underlies the Lupemban-MSA as at Sai Island. Another age for the Sangoan comes from TL dates (305$203 \mathrm{ka}$ ) that overlies Sangoan deposits at the site of Bété 1 in the Ivory Coast [156]. This suggests a potentially older origin for the Sangoan. However, Barham and Mitchell [29] note 
that the Béte 1 site has a high percentage of LCTs than other Sangoan assemblages such as Kalambo Falls and may indicate mixing of this open deposit. The Sai Island Sangoan is also the same age as the Lupemban-MSA deposits at Twin Rivers in Zambia if the dates of 266-172 ka are correct. This appears to show that the Sangoan and early MSA are contemporary in different areas of Africa with Lupemban-like MSA at Sai Island also being later than seen in Zambia. It is possible that the Sangoan here is of a similar age to that from Sai Island perhaps representing a spread from a more southern central area of Africa with the Kalambo and Kapthurin Formation Sangoan being older. However, if the Twin Rivers Lupemban is younger than $160-130 \mathrm{ka}$, as potentially seems the case based on the inverted speleothem ages, then it is of a similar age to the Lupemban-like MSA at Sai Island $(<162 \mathrm{ka})$ This is the same age as the Pinnacle Point 13B MSA in South Africa and material from Border Cave, Wonderwerk Cave, and Florisbad but much younger than the earliest Fauresmith from Kathu Pan at $417 \mathrm{ka}$. if this is the case then there is perhaps little reason to see the Sangoan at Kalambo as much older than its $182 \mathrm{ka}$ minimum age. If it is related to a climate shift then it may be MIS7 in age (240-190 ka).

It has often been suggested that the Sangoan is a woodworking specific industry [56] in part due to its discovery in heavily forested areas such as Zambia and the Congo. This is perhaps even more influenced by the association of wood at Kalambo Falls, one of the few sites to preserve such material. A number of undated Sangoan occurrences have also been described from South Africa, both along the costal dune systems of KwaZulu-Natal and the very northern Limpopo River region. If confirmed this suggests a distribution, if sparse, across almost all of Africa and appears to argue against either the Sangoan being a regional entity, or perhaps an environmentally specific one. The occurrence of the Sangoan in the Sudan further argues against this. Moreover, Rots and Van Peer [118] suggest the core axes are being used as digging rather than wood working tools.

Based on known occurrences, the Sangoan is, however, not widespread across most of South Africa, where the related transitional industry, the Fauresmith, has also been described. This too has been suggested to be a regionally or environmentally specific industry, but again, a lack of dates has hampered its comparison to other industries such as the Sangoan. The majority of the Fauresmith occurrences have been described from the River sequences of the Northern Cape and Free State. However, a number of potential Fauresmith sites; namely, Vereeniging and particularly Bushman's rock shelter occur at the very extremes of the Fauresmith range $[38,142]$. Only reanalysis and dating of these deposits and tools will help confirm if the Sangoan and Fauresmith are different regional entities or if the Fauresmith is perhaps an earlier entity than the Sangoan as the Sai Island dates suggest. The Acheulian levels at Kalambo Falls have some qualities distinctive of the Fauresmith, in terms of LCTs, although it don't seem to include many of the light duty tools often associated with it.

In South Africa, the Fauresmith industry has recently been dated in stratified deposits at Kathu Pan to at least $417 \mathrm{ka}$ and perhaps as old as $647 \mathrm{ka}$ and at Wonderwerk
Cave to sometimes between 305 and $179 \mathrm{ka}$. This is towards the older end of the Kapthurin Formation sequence. While the Kapthurin Formation is suggested to demonstrate independent evolution of all the traits that are used to classify the MSA [22] all these traits appear to occur at Kathu Pan during the Fauresmith. Of course, Kathu Pan is only one site and the Kapthurin Formation is many that indicate variation across both time and the landscape. Given that Kathu Pan and Wonderwerk are very close to each other the age of the Fauresmith and MSA at both sites suggests firstly that the Fauresmith is a relatively long lived entity, perhaps 200 ka and secondly that Fauremsith and MSA assemblages may overlap in the time range between 300-200 ka. Either that or the MSA assemblages from Kathu Pan represent the Fauremsith but simply do not have the elements that would be used to classify it as such.

At Wonderwerk, Chazan and Horwitz [147] and Beaumont and Vogel [47] certainly have different views on which layers are Fauresmith and which are MSA. This in itself asks the question regarding the difference between the Fauresmith and the MSA and whether as some researchers have suggested that the Fauresmith and other transitional industries should, in fact, represent the start of the MSA and that the presence of LCTs should be seen as merely a remnant of mode 2 technology in otherwise mode 3 dominant assemblages. Bruggemann et al. [117] argue that the Acheulian biface persisted at Abdur, possibly because it acquired a new, profitable use for the exploitation of aquatic resources by early modern humans. If this is the case, then it provides further evidence that LCTs are not distinctive only of the Acheulian and their persistence in some assemblages should not be used to equate them with the Acheulian but simply as a surviving ESA element in an otherwise MSA assemblage.

Prepared core technology, particularly Levallois, is inextricably linked to the MSA, but later stages of the ESA also document the use of prepared core reduction $[30,47,58$, 154, 157]. Good chronostratigraphic records are rare for this time period, but outside South Africa, there is some evidence that prepared core reduction may even date back to almost $800 \mathrm{ka}$ [158]. Giant cores [159] also referred to as Levallois-like [158] are known from the II-6 archaeological unit from Gesher Benot Ya'aqov in Israel. Goren-Inbar and Saragusti [158] suggest that biface production involved at least two well-established and different techniques: the Levallois and the Kombewa. These techniques produced predetermined, large-sized flakes that were modified into tools by a minimal amount of retouch [158]. A Technological and morphometric comparison between tools manufactured by the different techniques does not demonstrate any bimodal patterning of the end products [158].

Rink and Schwarcz [160] suggest the II-6 unit dates to around $681-623 \mathrm{ka}$ based on a range of combined U-Th/ESR ages. Older ages have been suggested based on the location of the Bruhnes-Matuyama boundary at $780 \mathrm{ka}$ in the lower unit II-7 and depositional rate estimates. However, given that the ESR ages are undertaken on fossils within the II- 6 sand unit, these ages should perhaps be taken as the true age of the site unless there is significant uncertainty in the ages. Many researchers have seemingly dismissed the ESR method as 
unreliable (see [161]). However, in the correct circumstances (i.e., low uranium concentrations as is the case of GBY), the method is reliable when a linear uptake model is used based on comparisons with other geochronological methods (see $[19,79])$. The palaeomagentic reversal occurs in the base of clay unit II-7 and as such the entire of II-7 was deposited after the transition as well as a change of sedimentation and potential hiatus between units II-7 and II-6. As such, the II-6 unit could not be as old as $\sim 780 \mathrm{ka}$ as is most often quoted [162]. There is also a suggestion from the fauna [163] that the site has a number of species not seen in Europe until closer to $600 \mathrm{ka}$. Rink and Schwarcz [160] suggest that a hiatus in deposition may be responsible for this difference in palaeomagnetic and ESR age estimates. However, Rink and Schwarcz's [160] study suffers from a common problem in ESR studies (see discussion in $[67,79]$ for other examples), where all the ages are averaged together to create a mean value for different units or teeth with vastly different ages where the reasons and mechanisms for the differencing ages has not been established. If the ESR dates (linear uptake, $40 \%$ moisture) of Rink and Schwarcz [160] are separated by units; the lower II-7 deposit has an optimal age of between 718 and $555 \mathrm{ka}$ (max age range $767-534 \mathrm{ka}$ ) and the upper II-6 unit has an optimal age of 708-559 ka (max age range of 718-492 ka). The upper age range for the top of the II7 deposit, which contains the $\sim 780$ ka Bruhnes-Matuyama boundary in its base, is $767 \mathrm{ka}$, which is not much younger than $780 \mathrm{ka}$ (moreover, recent estimates put the boundary at $773 \mathrm{ka} \mathrm{[164]).} \mathrm{This} \mathrm{suggests} \mathrm{that} \mathrm{the} \mathrm{II-6} \mathrm{archaeology}$ most likely dates to sometime between $\sim 700$ and $\sim 550 \mathrm{ka}$, although a slightly older age cannot be ruled out.

These cores are not too dissimilar to both the large LCT cores described for the Kapthurin Formation [106, 109] between 509-272 ka or the Victoria West Cores of South Africa. Sharon and Beaumont [43] have suggested that Victoria West cores were also developed as a prepared core technique within the Acheulian as a means of producing ready-made blanks for LCTs. Part of the problem in southern Africa is that no Victoria West core bearing sites have been accurately dated and few are well stratified. Victoria West technology has been recovered from stratified Acheulian contexts in stratum $2 \mathrm{a}$ at Canteen Koppie in South Africa [68]. The stratum 2a contains an Acheulian assemblage that is overlain by Fauresmith material in stratum 1 (Hutton sands), where it is then followed by an MSA assemblage which has dates of 120-80 ka [165]. As such, the Victoria West technology appears to be associated with terminal Acheulian artefacts and is older than the Fauremsith. While the Victoria West layers at Canteen Kopjie are undated, if the ages for Kathu Pan are extrapolated, then they should be older than $540-470 \mathrm{ka}$ and perhaps not too dissimilar in age from those from GBY at $700-550 \mathrm{ka}$. This points to a widespread use of this giant core technology around 700-300 ka in Africa and the Levant in late Acheulian and transitional industries. Whether these early prepared core technologies for making large blanks for LCTs are protoLevallois and evolved directly to MSA Levallois technology or para-Levallois is beyond the scope of this paper (see $[41,43])$. However, in the Kapthurin Formation, there seems to be a relative progression from these giant cores to centripetal and then convergent Levallois cores and flakes [109]. Lycett [41] suggests that Victoria West cores show independent development of prepared core technology from that of Levallois technology, and as such it is "para-Levallois" rather than "proto-Levallois". However, the Victoria West is chronologically older than the Levallois technology of the Fauresmith and similar progression as just described for the Kapthurin Formation could also be argued for South Africa.

Blades also seem to be a component of either the late Acheulian or the beginning of this transitional phase as shown by their first occurrence in the Kapthurin Formation between 545 and $509 \mathrm{ka}$ and in the Fauresmith at Kathu Pan. Large blades were one of the earliest indicators of the Fauresmith and these are noted in the Wonderwerk occurrence [147]. As noted before, Tryon et al. [54] and Tryon and McBrearty [109] suggest that diversification of Levallois technology as seen at Koimilot by $\sim 250 \mathrm{ka}$ and the occurrence of convergent Levallois points and cores stands as the marker of the early MSA. Tryon et al. [54] note that Levallois technology for making LCTS occurs by 350-300 ka based on ESR age estimates at the Grotte des Rhinocéros and by OSL at Cap Chatelier [166] in North-west Africa, and Levallois-like cores make from LCTs at Kharga Oasis (Egypt) between 400-300 ka based on U-series dating of tufa [167].

Mcbrearty [22] also suggests that the fundamental change from the ESA to the MSA is the end of LCTs and a shift to projectile point technology. Of course, it should be noted that Acheulian bearing hominins in Europe were utilising an entirely wooden projectile technology for hunting as shown by the occurrence of the Schöningen spears at either 400 (MIS 11 [157]) or $\sim 310 \mathrm{ka}$ (MIS 9d-e; [168]) but were seemingly still disarticulating their kill with LCTs. Whether a similar wooden projectile technology was being used by hominins in Africa is almost impossible to tell given the almost complete lack of preservation of such organic remains in most MSA sites. The exceptions are two wooden tools from Floor 1 at Kalambo Falls in Zambia [30, 56] and one from Florisbad in South Africa [13]. Other sites where large pieces of wood have been recovered include the Acheulian sites of Amanzi Springs [73] and Gesher Benot Ya'aqov [169]. Despite the discovery of significant amounts of wood from these deposits, no tools have been noted. The Kalambo falls tools are reminiscent in some ways of the European "spears" and are associated with large wellformed cleavers from the Acheulian bearing Floor 2, below the Sangoan. Given their context these wood tools might be older than those from Europe and might point to a wooden projectile point technology in the late Acheulian, complimenting the earlier LCT technology. At most sites, the only clue would be in finding injury patterns on faunal remains indicative of such activities. In a similar vein, the co-occurrence of LCTs and projectile point technology in the Sangoan and Fauresmith may reflect similar activity patterns, or as McBrearty [22] suggests that the mix of technologies may, in fact, represent different hominins using different technologies at the same time in the same regions of Africa.

All this has somewhat blurred the distinction between the terminal Acheulian, the transitional industries, and the 
earliest MSA and highlights the need to perhaps define a transitional phase as per Clark [28] or to perhaps redefine the MSA as an entity as suggested by Beaumont and Vogel [47] and Van Peer et al. [65]. Certainly, the end of an industrial complex should not be defined on the last appearance of its classic tool form but by the introduction of new technology. However, in some views, this change should only be defined when this new form has become dominant [27], creating a rather arbitrary line. Goodwin and van Riet Lowe [26] defined the MSA as being intermediate between the ESA and LSA, both temporally and technologically. It was in part defined by a lack of LCTS at its upper age limit and lack of microliths at its younger age limit. MSA industries such as the Howieson's Poort have shown that microlithic technology does occasionally occur within the later phases of the MSA, perhaps in response to distinct climatic fluctiuations (68-57 ka [50]). The MSA was later recognized as being blade based, rather than flake based, and that it included the common use of the Levallois technique $[120,170]$. The sites described above show that all these markers of the MSA, that is, blades, Levallois technology begin to occur contemporaneously with LCTs between 548 and $272 \mathrm{ka}$ in both eastern and southern Africa [107, 108, 148]. Kathu Pan and Bundu Farm suggest that even at this early time period LCTs seem to make up a much smaller component of the stone tool assemblages than at earlier Acheulian sites.

Klein [171] notes that many researchers (e.g., [39, 40, 172]) have moved beyond Goodwin's 1928 [49] classification of the MSA to include any industries which are characterized principally by retouched and unretouched flakes of various kinds and/or which are chronologically intermediate between the hand axe industries of the ESA and the largely microlithic industries of the LSA. Klein notes that the prominence of triangular flakes with convergent dorsal scars and faceted butts is no longer an important criterion as they do not occur in all assemblages, many of which would be considered "classic MSA". The example Klein [171] provides is the Mossel Bay Industry from Cape St. Blaze Cave. Unfortunately, this is an industry whose age is still questionable. If a similar age to material from the nearby caves at Pinnacle Point it could be of MIS 6 age (200-120 ka) but there are definite differences [123], so perhaps it is even older or represents another part of MIS 6 variation. As most lithic specialists would concede Goodwin emphasized in his early papers that the MSA was not homogeneous in time and space and in this sense many researchers would see the classification of the Fauresmith into the ESA or MSA a semantic one or an attempt at pigeonholing. However, in archaeology, as with geology, classifications, frameworks, and the boundaries between these entities need to be established somewhere. With the ever increasing age for the first LSA industries based on the presence of microlithics and mode 4 and 5 technology and the retention of LCTs (particularly hand axes) as the defining character of the Acheulian, the MSA is beginning to be squeezed into an ever decreasing age range with little potential significance and no association with the hominin record.
Cornelia-Uitzoek and arguably Elandsfontein and Duinefontein II are Acheulian assemblages that date to around 1.1-0.8 Ma, and all three do not contain prepared core technology or other technology reminiscent of the MSA. A such, they seem to represent what might be termed a middle Acheulian period between the earliest Acheulian found prior to $1.1 \mathrm{Ma}$ at Sterkfontein and the oldest Vaal River deposits and the final Acheulian period that contains Victoria West Giant prepared core technology such as Canteen Kopjie. It is clear that the MSA first occurs before the advent of anatomically modern humans, and yet, there is also potential evidence that some of these modern human are also still utilising ESA technology. The co-occurrence of MSA technologies at Florisbad with $H$. helmei at $\sim 260 \mathrm{ka}$ and $H$. sapiens with LCTs at $\sim 160 \mathrm{ka}$ is the opposite of what might be expected if these industries were being made by different hominins based on the exclusive co-occurrence of the MSA with $H$. sapiens fossils after $120 \mathrm{ka}$. Many researchers see the beginning of the Acheulian as a clear change in hominin behaviour related to the appearance of $H$. ergaster [29] and the middle Acheulian site of Elandsfontein, without prepared core technology is associated with $H$. erectus or very early $H$. rhodesiensis. The first occurrence of MSA-like characters in the Fauresmith is a time period where archaic forms of Homo sapiens begin to occur in Africa in the form of Homo rhodesiensis and then $H$. helmei. Unfortunately, the Middle Pleistocene hominin record of southern Africa is very spartan and still not well dated. Certainly, the traditional start of the MSA between 300 and $200 \mathrm{ka}$ associates it with H. helmei fossils such as the Florisbad cranium and not $H$. sapiens. It seems likely that the beginnings of MSA style technology in the Fauresmith began with $H$. rhodesiensis and gradually evolved through time to incorporate a greater range of technology, including diversity in projectile point, composite stone tool, and Levallois technology by the time H. helmei is first seen soon after $300 \mathrm{ka}$. By the time the Fauresmith is noted, it has all the features of the MSA with small prepared cores and points that may very well represent the beginning of composite tool technology and also projectile points. A number of the Kathu Pan tools certainly look like they were made as projectile points (see [148, Figure 6]. The Sangoan has certainly been suggested to contain some of the first hafted stone tools, and it is perhaps this major technological change along with the classic MSA forms that occur in the Fauresmith that makes these two entities either regional variants at the beginning of the MSA or perhaps temporally distinct industries during a transitional phase between the ESA and MSA. The switch is in essence one of scale with the period represented by LCTs and prepared cores for making LCTs representing the beginnings of a transitional period in both stone tool industries and hominin species. As the Acheulian is inextricably linked to $H$. ergaster and $H$. erectus, so too, the beginnings of MSA technology appear to occur in the Fauresmith with the advent of archaic H. sapiens ( $H$. rhodesiensis/H. helmei) and come to full flourishion before the advent of the first modern humans at $\sim 200-150 \mathrm{ka}$. Only better dating of the Fauresmith and Sangoan sites will help answer what will most likely turn out to be an extremely complex process of transition from the ESA to the MSA. 


\section{Acknowledgments}

The authors Thanks Darren Curnoe for inviting him to write this paper for this special issue of IJEB and all the researchers he has worked with in South Africa over the last 15 year and who have granted him access to work or visit the various sites (David Braun, James Brink, Ron Clarke, Kevin Kuykendall, Curtis Marean, David Morris, Kaye Reed, and Lyn Wadley). A special thanks to the late Tim Partridge who strived to better understand the age of the early hominin bearing sites of southern Africa. He thanks also the staff of the University of Liverpool Geomagnetism Laboratory where he has undertaken much of his palaeomagnetic work. This work was supported by ARC Discovery Grant no. DP0877603 and research money from the UNSW Faculty of Medicine. He Thanks two anonymous referees for extremely useful comments on an earlier draft.

\section{References}

[1] G. Ogg, "International Stratigraphic Chart," International Commission on Stratigraphy, 2009.

[2] T. M. Cronin, Paleoclimates: Understanding Climate Change Past and Present, Columbia University Press, 2009.

[3] J. P. Noonan, G. Coop, S. Kudaravalli et al., "Sequencing and analysis of Neanderthal genomic DNA," Science, vol. 314, no. 5802, pp. 1113-1118, 2006.

[4] J. L. Bischoff, R. W. Williams, R. J. Rosenbauer et al., "High-resolution U-series dates from the Sima de los Huesos hominids yields 600 kyrs: implications for the evolution of the early Neanderthal lineage," Journal of Archaeological Science, vol. 34, no. 5, pp. 763-770, 2007.

[5] R. G. Klein, G. Avery, K. Cruz-Uribe, and T. E. Steele, "The mammalian fauna associated with an archaic hominin skullcap and later Acheulean artifacts at Elandsfontein, Western Cape Province, South Africa," Journal of Human Evolution, vol. 52, no. 2, pp. 164-186, 2007.

[6] E. Tamrat, N. Thouveny, M. Taïeb, and N. D. Opdyke, "Revised magnetostratigraphy of the Plio-Pleistocene sedimentary sequence of the Olduvai Formation (Tanzania)," Palaeogeography, Palaeoclimatology, Palaeoecology, vol. 114, no. 2-4, pp. 273-283, 1995.

[7] A. S. Woodward, "A new cave man from Rhodesia, South Africa," Nature, vol. 108, no. 2716, pp. 371-372, 1921.

[8] Q. B. Hendey, "The late Cenozoic Carnivora of the southwestern Cape Province," Annals of the South African Museum, vol. 63, pp. 1-369, 1974.

[9] A. I. R. Herries, K. E. Reed, K. L. Kuykendall, and A. G. Latham, "Speleology and magnetobiostratigraphic chronology of the Buffalo Cave fossil site, Makapansgat, South Africa," Quaternary Research, vol. 66, no. 2, pp. 233-245, 2006.

[10] A. I. R. Herries, J. S. Brink, B. Bousman et al., "A palaeomagnetic age of about 990,000 years for the CorneliaUitzoek fossil vertebrate, hominin and Acheulian site, South Africa," American Journal of Physical Anthropology, vol. 138, supplement 48, p. 149, 2009.

[11] T. F. Dreyer, "A human skull from Florisbad, Orange Free State, with a note on the endocranial cast, by C. U. Ariens Kappers," Proceedings of the Academy of Science of Amsterdam, vol. 38, pp. 119-128, 1935.
[12] R. Grün, J. S. Brink, N. A. Spooner et al., "Direct dating of Florisbad homini," Nature, vol. 382, no. 6591, pp. 500-501, 1996.

[13] K. Kuman, M. Inbar, and R. J. Clarke, "Palaeoenvironments and cultural sequence of the Florisbad Middle Stone Age hominid site, South Africa," Journal of Archaeological Science, vol. 26, no. 12, pp. 1409-1425, 1999.

[14] R. S. Lacruz, J. S. Brink, J. Hancox et al., "Palaeontology, geological context and palaeoenvironmental implications of a Middle Pleistocene faunal assemblage from the Gladysvale Cave, South Africa," Palaeontologia Africana, vol. 38, pp. 99$114,2002$.

[15] I. McDougall, F. H. Brown, and J. G. Fleagle, "Stratigraphic placement and age of modern humans from Kibish, Ethiopia," Nature, vol. 433, no. 7027, pp. 733-736, 2005.

[16] J. D. Clark, Y. Beyene, G. WoldeGabriel et al., "Stratigraphic, chronological and behavioural contexts of Pleistocene Homo sapiens from Middle Awash, Ethiopia," Nature, vol. 423, no. 6941, pp. 747-752, 2003.

[17] C. W. Marean, P. J. Nilssen, K. Brown, A. Jerardino, and D. Stynder, "Paleoanthropological investigations of Middle Stone Age sites at Pinnacle Point, Mossel Bay (South Africa): archaeology and hominid remains from the 2000 field season," Paleoanthropology, vol. 2, pp. 14-83, 2004.

[18] C. W. Marean, M. Bar-Matthews, J. Bernatchez et al., "Early human use of marine resources and pigment in South Africa during the Middle Pleistocene," Nature, vol. 449, no. 7164, pp. 905-908, 2007.

[19] R. Grün, "Direct dating of human fossils," Yearbook of Physical Anthropology, vol. 49, pp. 2-48, 2006.

[20] J. K. Feathers, "Luminescence dating in less than ideal conditions: Case studies from Klasies River main site and Duinefontein, South Africa," Journal of Archaeological Science, vol. 29, no. 2, pp. 177-194, 2002.

[21] D. D. Stynder, F. Brock, J. C. Sealy, S. Wurz, A. G. Morris, and T. P. Volman, "A mid-Holocene AMS C date for the presumed upper Pleistocene human skeleton from Peers Cave, South Africa," Journal of Human Evolution, vol. 56, no. 4, pp. 431434, 2009.

[22] S. McBrearty, "Patterns of technological change at the origin of Homo sapiens," Before Farming, vol. 2003/3, pp. 1-5, 2003.

[23] S. Mcbrearty and A. S. Brooks, "The revolution that wasn't: a new interpretation of the origin of modern human behavior," Journal of Human Evolution, vol. 39, no. 5, pp. 453-563, 2000.

[24] M. Domínguez-Rodrigo, A. Mabulla, L. Luque et al., "A new archaic Homo sapiens fossil from Lake Eyasi, Tanzania," Journal of Human Evolution, vol. 54, no. 6, pp. 899-903, 2008.

[25] C. van Riet Lowe, "The Fauresmith coup de poing," South African Journal of Science, vol. 24, pp. 502-505, 1927.

[26] A. J. H. Goodwin and C. van Riet Lowe, "The Stone Age cultures of South. Africa," Annals of the South African Museum, vol. 27, pp. 1-289, 1929.

[27] A. J. H. Goodwin, The Loom of Prehistory, vol. 2 of South African Archaeological Society Handbook Series, No. 2, The Society, 1946.

[28] J. D. Clark, The Prehistory of Southern Africa, Penguin, Harmondsworth, UK, 1959.

[29] L. Barham and P. Mitchell, The First Africans: African Archaeology from the Earliest Toolmakers to Most Recent Foragers, Cambridge World Archaeology Series, Cambridge University Press, Cambridge, UK, 2008.

[30] J. D. Clark, Kalambo Falls Prehistoric Site Volume 3, The Earlier Cultures: Middle and Earlier Stone Age, University of California, Berkeley, Calif, USA, 2001. 
[31] J. McNabb, F. Binyon, and L. Hazelwood, "The large cutting tools from the South African Acheulean and the question of social traditions," Current Anthropology, vol. 45, no. 5, pp. 653-677, 2004.

[32] A. J. H. Goodwin, “The Stone Ages in South Africa," Journal of the International African Institute, vol. 2, pp. 174-182, 1929.

[33] L. Peringuey, "The Stone Ages of South Africa," Annals of the South African Museum, vol. 8, 1911.

[34] A. J. H. Goodwin, "South African Archaeology," Man, vol. 27, pp. 29-31, 1927.

[35] L. S. B. Leakey, Olduvai Gorge: A Report on the Evolution of the Hand-Axe Culture in Beds 1-IV, Cambridge University Press, Cambridge, UK, 1951.

[36] M. D. Leakey, "Preliminary survey of the cultural material from Beds 1 and II, Olduvai Gorge, Tanzania," in Background to Human Evolution in Africa, W. W. Bishop and J. D. Clark, Eds., pp. 417-446, University of Chicago Press, Chicago, Ill, USA, 1967.

[37] J. S. Brink, "The taphonomy of an Early/Middle Pleistocene hyaena burrow at Cornelia-Uitzoek, South Africa," Revue de Paleobiologie, vol. 23, no. 2, pp. 731-740, 2004.

[38] S. G. Le Roux and S. F. Le Roux, "A New South African Chelles-Acheul Site near Vereeniging," The South African Archaeological Bulletin, vol. 14, pp. 138-141, 1959.

[39] R. Mason, Prehistory of the Transvaal, University of the Witwatersrand Press, Johannesburg, South Africa, 1962.

[40] C. M. Keller, Montagu Cave in Prehistory: A Descriptive Analysis, vol. 28 of Anthropological Records, University of California Press, Berkeley, Calif, USA, 1973.

[41] S. J. Lycett, "Are Victoria West cores "proto-Levallois"? A phylogenetic assessment," Journal of Human Evolution, vol. 56, no. 2, pp. 175-191, 2009.

[42] S. J. Lycett, N. V. Cramon-Taubadel, and J. A. J. Gowlett, "A comparative 3D geometric morphometric analysis of Victoria West cores: implications for the origins of Levallois technology," Journal of Archaeological Science, vol. 37, no. 5, pp. 1110-1117, 2010.

[43] G. Sharon and P. Beaumont, "Victoria West-a highly standardized prepared core technology," in Axe Age: Acheulian Toolmaking from Quarry to Discard, N. Goren-Inbar and G. Sharon, Eds., pp. 181-199, Equinox, London, UK, 2006.

[44] A. J. H. Goodwin, "South African stone implement industries," South African Journal of Science, vol. 23, pp. 784-788, 1926.

[45] C. van Riet Lowe, "The archaeology of the Vaal River Basin," Memoirs of the Geological Survey of the Union of South Africa, vol. 35, pp. 361-381, 1937.

[46] C. van Riet Lowe and C. van der Elst, "Two New African Chelles-Acheul or Stellenbosch Stage I Sites," The South African Archaeological Bulletin, vol. 4, pp. 111-115, 1949.

[47] P. B. Beaumont and J. C. Vogel, "On a timescale for the past million years of human history in central South Africa," South African Journal of Science, vol. 102, no. 5-6, pp. 217228, 2006.

[48] A. J. H. Goodwin, "South African Archaeology," Man, vol. 27, pp. 29-31, 1927.

[49] A. J. H. Goodwin, "An introduction to the Middle Stone Age of South Africa," South African Journal of Science, vol. 25, pp. 410-418, 1928.

[50] Z. Jacobs, R. G. Roberts, R. F. Galbraith et al., "Ages for the Middle Stone Age of southern Africa: implications for human behavior and dispersal," Science, vol. 322, no. 5902, pp. 733$735,2008$.
[51] C. G. Sampson, The Stone Age archaeology of southern Africa, Academic Press, New York, NY, USA, 1974.

[52] C. van Riet Lowe, "The Evolution of the Levallois Technique in South Africa," Man, vol. 45, pp. 49-59, 1945.

[53] C. van Riet Lowe, "The Vaal River chronology: an up-to-date summary," The South African Archaeological Bulletin, vol. 7, pp. 135-149, 1952.

[54] C. A. Tryon, S. McBrearty, and P. J. Texier, "Levallois lithic technology from the Kapthurin Formation, Kenya: acheulian origin and Middle Stone Age diversity," African Archaeological Review, vol. 22, no. 4, pp. 199-229, 2005.

[55] J. D. Clark, “The later Pleistocene cultures of Africa," Science, vol. 150, no. 3698, pp. 833-847, 1965.

[56] J. D. Clark, "An early Upper Pleistocene site at the Kalambo Falls on the Northern Rhodesia/Tanganyika Border," The South African Archaeological Bulletin, vol. 9, pp. 51-56, 1954.

[57] J. D. Clark, “The Prehistoric Origins of African Culture," The Journal of African History, vol. 5, pp. 161-183, 1964.

[58] S. McBrearty, "The Sangoan-Lupemban and Middle Stone Age sequence at the Muguruk site, western Kenya," World Archaeology, vol. 19, no. 3, pp. 388-420, 1987.

[59] R. R. Inskeep, "Some problems relating to the Early Stone Age in South Africa," South African Archaeological Bulletin, vol. 24, pp. 174-181, 1969.

[60] A. J. B. Humphreys, "The role of raw material and the concept of the Fauresmith," The South African Archaeological Bulletin, vol. 25, pp. 139-144, 1970.

[61] R. J. Mason, "Some South African stone age cultures," Nature, vol. 183, no. 4658, pp. 377-379, 1959.

[62] R. J. Gibbon, The fluvial history of the lower Vaal River catchment, Ph.D. thesis, University of the Witwatersrand, South Africa, 2009.

[63] G. M. Leader, Early Acheulean in the Vaal River basin, Rietputs Formation, Northern Cape Province, South Africa, Ph.D. thesis, University of the Witwatersrand, South Africa, 2009.

[64] O. Davies, “The 'Sangoan' industries," Annals of the Natal Museum, vol. 22, pp. 885-911, 1976.

[65] P. Van Peer, R. Fullagar, S. Stokes et al., "The Early to Middle Stone Age Transition and the emergence of modern human behaviour at site 8-B-11 Sai Island, Sudan," Journal of Human Evolution, vol. 45, no. 2, pp. 187-193, 2003.

[66] K. Kuman, "The Earlier Stone Age in South Africa: site context and the influence of cave studies," in Breathing Life into Fossils: Taphonomic Studies in Honour of C.K. (Bob) Brain, T. R. Pickering, K. Schick, and N. Toth, Eds., pp. 181198, Stone Age Institute Press, Bloomington, Ind, USA, 2007.

[67] A. I. R. Herries, D. Curnoe, and J. W. Adams, "A multidisciplinary seriation of early Homo and Paranthropus bearing palaeocaves in southern Africa," Quaternary International, vol. 202, no. 1-2, pp. 14-28, 2009.

[68] P. Beaumont and J. McNabb, "Canteen Kopje: the recent excavations," The Digging Stick, vol. 17, pp. 3-6, 2000.

[69] P. Beaumont, "Kathu Pan and Kathu Townlands / Uitkoms," in Archaeology in the Northern Cape: Some Key Sites, D. Morris and P. Beaumont, Eds., pp. 50-53, McGregor Museum, Kimberley, South Africa, 2004.

[70] P. Beaumont, "Rooidam 1 \& 2 and Biesiesput," in Guide to the Archaeological Sites in the Northern Cape, P. Beaumont and D. Morris, Eds., pp. 19-21, McGregor Museum, Kimberley, South Africa, 1990. 
[71] R. G. Klein, G. Avery, K. Cruz-Uribe et al., "Duinefontein 2: an Acheulean site in the western Cape province of South Africa," Journal of Human Evolution, vol. 37, no. 2, pp. 153190, 1999.

[72] P. Beaumont, "Wonderwerk Cave," in Archaeology in the Northern Cape: Some Key Sites, D. Morris and P. Beaumont, Eds., pp. 50-53, McGregor Museum, Kimberley, South Africa, 2004.

[73] H. J. Deacon, "Planting an idea: an Archaeology of Stone Age Gatherers in South Africa," The South African Archaeological Bulletin, vol. 48, pp. 86-93, 1993.

[74] K. Kuman, R. J. U. Gibbon, H. Kempson et al., "Stone Age signatures in northernmost South Africa: early archaeology of the Mapungubwe National Park and vicinity," in From Tools to Symbols: From Early Hominids to Modern Humans, F. D'Errico and L. Backwell, Eds., Witwatersrand University Press, 2005.

[75] M. Chazan, H. Ron, A. Matmon et al., "Radiometric dating of the Earlier Stone Age sequence in Excavation I at Wonderwerk Cave, South Africa: preliminary results," Journal of Human Evolution, vol. 55, no. 1, pp. 1-11, 2008.

[76] R. J. Gibbon, D. E. Granger, K. Kuman, and T. C. Partridge, "Early Acheulean technology in the Rietputs Formation, South Africa, dated with cosmogenic nuclides," Journal of Human Evolution, vol. 56, no. 2, pp. 152-160, 2009.

[77] K. Kuman and R. J. Clarke, "Stratigraphy, artefact industries and hominid associations for Sterkfontein, Member 5," Journal of Human Evolution, vol. 38, no. 6, pp. 827-847, 2000.

[78] D. Curnoe, A contribution to the question of early Homo in southern Africa: researches into dating, taxonomy and phylogeny reconstruction, Ph.D. thesis, Australian National University, Canberra, Australia, 1999.

[79] A. I.R. Herries and J. Shaw, "Palaeomagnetic analysis of the Sterkfontein palaeocave deposits: Implications for the age of the hominin fossils and stone tool industries," Journal of Human Evolution, vol. 60, no. 5, pp. 523-539, 2011.

[80] A. I. R. Herries, P. Hopley, J. Adams, D. Curnoe, and M. Maslin, "Geochronology and palaeoenvironments of the South African early hominin bearing sites: a reply to 'Wrangham et al., 2009: Shallow-Water Habitats as Sources of Fallback Foods for Hominins," American Journal of Physical Anthropology, vol. 143, pp. 640-646, 2010.

[81] R. Pickering and J. D. Kramers, "Re-appraisal of the stratigraphy and determination of new $\mathrm{U}-\mathrm{Pb}$ dates for the Sterkfontein hominin site, South Africa," Journal of Human Evolution, vol. 59, no. 1, pp. 70-86, 2010.

[82] T. C. Partridge, "Hominid-bearing cave and tufa deposits," in The Cenozoic of southern Africa, T. C. Partridge and R. R. Maud, Eds., pp. 100-125, Oxford University Press, Oxford, UK, 2000.

[83] H. J. O’Regan and S. C. Reynolds, “An ecological reassessment of the southern African carnivore guild: a case study from Member 4, Sterkfontein, South Africa," Journal of Human Evolution, vol. 57, no. 3, pp. 212-222, 2009.

[84] E. S. Vrba, "Biostratigraphy and chronology, based particularly on Bovidae, of southern hominid associated assemblages: Makapansgat, Sterkfontein, Taung, Kromdraai, Swartkrans; also Elandsfontein (Saldanha), Broken Hill (now Kabwe) and Cave of Hearths," in 1èr Congrès International de Paléontologie Humaine, CNRS, Nice, France, 1982.

[85] H. J. O'Regan, "A revision of the Carnivora from M5, Sterkfontein, South Africa, based on a reassessment of published material and site stratigraphy," Annals of the Transvaal Museum, vol. 44, pp. 209-214, 2007.
[86] R. Pickering, J. D. Kramers, P. J. Hancox, D. J. de Ruiter, and J. D. Woodhead, "Contemporary Flowstone Development Links Early Hominin Bearing Cave. Deposits in South Africa," Earth and Planetary Science letters, vol. 306, pp. 2332, 2011.

[87] S. C. Reynolds, "Where the wild things were: spatial and temporal distribution of carnivores in the cradle of humankind (Gauteng, South Africa) in relation to the accumulation of mammalian and hominin assemblages," Journal of Taphonomy, vol. 8, pp. 233-257, 2010.

[88] B. Asfaw, Y. Beyene, G. Suwa et al., "The earliest Acheulean from Konso-Gardula," Nature, vol. 360, no. 6406, pp. 732$735,1992$.

[89] S. Katoh, S. Nagaoka, G. WoldeGabriel et al., "Chronostratigraphy and correlation of the Plio-Pleistocene tephra layers of the Konso Formation, southern Main Ethiopian Rift, Ethiopia," Quaternary Science Reviews, vol. 19, no. 13, pp. 1305-1317, 2000.

[90] S. Nagaoka, S. Katoh, G. Woldegabriel et al., "Lithostratigraphy and sedimentary environments of the hominid-bearing Pliocene-Pleistocene Konso Formation in the southern Main Ethiopian Rift, Ethiopia," Palaeogeography, Palaeoclimatology, Palaeoecology, vol. 216, no. 3-4, pp. 333-357, 2005.

[91] H. Roche and M. Kibunjia, "Plio-Pleistocene sites from Nachukui Formation, west of Lake Turkana, KenyaLes sites archeologiques plio-pleistocenes de la Formation de Nachukui, west Turkana, Kenya," Comptes Rendus - Academie des Sciences, Serie II, vol. 318, no. 8, pp. 1145-1151, 1994.

[92] T. E. Cerling and R. L. Hay, "An isotopic study of paleosol carbonates from Olduvai Gorge," Quaternary Research, vol. 25, no. 1, pp. 63-78, 1986.

[93] K. Kuman, "The archaeology of Sterkfontein-past and present," Journal of Human Evolution, vol. 27, no. 6, pp. 471495, 1994.

[94] A. Ronen, “The oldest human groups in the Levant," Comptes Rendus - Palevol, vol. 5, no. 1-2, pp. 343-351, 2006.

[95] A. S. Field, An analytical and comparative study of the Earlier Stone Age archaeology of the Sterkfontein Valley, M.S. dissertation, University of the Witwatersrand, 1999.

[96] J. D. Clark, J. De Heinzelin, K. D. Schick et al., "African Homo erectus: old radiometric ages and young Oldowan assemblages in the Middle Awash Valley, Ethiopia," Science, vol. 264, no. 5167, pp. 1907-1910, 1994.

[97] K. Cruz-Uribe, R. G. Klein, G. Avery et al., "Excavation of buried late Acheulean (mid-quaternary) land surfaces at Duinefontein 2, Western Cape Province, South Africa," Journal of Archaeological Science, vol. 30, no. 5, pp. 559-575, 2003.

[98] S. G. Kang, X. L. Wang, X. N. Li, and Y. C. Lu, "Anomalous fading of the IRSL signal of polymineral grains in Chinese loess," Radiation Measurements, vol. 45, no. 1, pp. 22-28, 2010.

[99] X. L. Wang, A. G. Wintle, and Y. C. Lu, "Thermally transferred luminescence in fine-grained quartz from Chinese loess: basic observations," Radiation Measurements, vol. 41, no. 6, pp. 649-658, 2006.

[100] G. Hall, R. Pickering, R. Lacruz, J. Hancox, L. R. Berger, and P. Schmid, "An Acheulean handaxe from Gladysvale Cave site, Gauteng, South Africa," South African Journal of Science, vol. 102, no. 3-4, pp. 103-105, 2006.

[101] A. I. R. Herries, Magnetostratigraphic seriation of South African hominin palaeocaves, Ph.D. thesis, Faculty of Science, University of Liverpool, Liverpool, UK, 2003. 
[102] A. I. R. Herries and A. G. Latham, "Archaeomagnetic studies at the Cave of Hearths," in The Cave of Hearths: Makapan Middle Pleistocene Research Project, J. McNabb and A. G. M. Sinclair, Eds., University of Southampton Series in Archaeology 1, chapter 5, pp. 59-64, Archaeopress, Oxford, UK, 2009.

[103] J. McNabb, “The ESA Stone Tool Assemblage from the Cave of Hearths, Beds 1-3," in The Cave of Hearths: Makapan Middle Pleistocene Research Project, J. McNabb and A. G. M. Sinclair, Eds., University of Southampton Series in Archaeology 1, pp. 75-104, Archaeopress, Oxford, UK, 2009.

[104] R. Grün, "Direct dating of South African human fossils," in Proceedings of the 15th Biennial Conference of the Southern African Society for Quaternary Research, Johannesburg, South Africa, 2003.

[105] A. P. Roberts, "Geomagnetic excursions: knowns and unknowns," Geophysical Research Letters, vol. 35, no. 17, Article ID L17307, 2008.

[106] A. L. Deino and S. McBrearty, "Ar/Ar dating of the Kapthurin Formation, Baringo, Kenya," Journal of Human Evolution, vol. 42, no. 1-2, pp. 185-210, 2002.

[107] C. R. Johnson and S. McBrearty, “500,000 year old blades from the Kapthurin Formation, Kenya," Journal of Human Evolution, vol. 58, no. 2, pp. 193-200, 2010.

[108] C. A. Tryon and S. McBrearty, "Tephrostratigraphy and the Acheulian to Middle Stone Age transition in the Kapthurin Formation, Kenya," Journal of Human Evolution, vol. 42, no. 1-2, pp. 211-235, 2002.

[109] C. A. Tryon and S. McBrearty, "Tephrostratigraphy of the Bedded Tuff Member (Kapthurin Formation, Kenya) and the nature of archaeological change in the later middle Pleistocene," Quaternary Research, vol. 65, no. 3, pp. 492-507, 2006.

[110] C. A. Tryon, "'Early" Middle Stone Age lithic technology of the Kapthurin Formation (Kenya)," Current Anthropology, vol. 47, no. 2, pp. 367-375, 2006.

[111] C. A. Tryon, N. T. Roach, and M. A. V. Logan, “The Middle Stone Age of the northern Kenyan Rift: age and context of new archaeological sites from the Kapedo Tuffs," Journal of Human Evolution, vol. 55, no. 4, pp. 652-664, 2008.

[112] J. F. Evernden and G. H. Curtis, "The potassium-argon dating of late Cenozoic rocks in East Africa and Italy," Current Anthropology, vol. 6, pp. 343-385, 1965.

[113] L. E. Morgan and P. R. Renne, "Diachronous dawn of Africa's Middle Stone Age: new ${ }^{40} \mathrm{Ar} / 3^{9} \mathrm{Ar}$ ages from the Ethiopian Rift," Geology, vol. 36, no. 12, pp. 967-970, 2008.

[114] R. L. Laury and C. C. Albritton, "Geology of Middle Stone Age archaeological sites in the Main Ethiopian Rift Valley," Geological Society of America Bulletin, vol. 86, pp. 999-1011, 1975.

[115] R. Schild and F. Wendorf, "Gademotta and Kulkuletti and the ages for the beginning of the Middle Paleolithic in Africa," Israel Prehistoric Society Journal, vol. 35, pp. 117-142, 2005.

[116] A. R. Millard, "A critique of the chronometric evidence for hominid fossils: I. Africa and the Near East 500-50 ka," Journal of Human Evolution, vol. 54, no. 6, pp. 848-874, 2008.

[117] J. H. Bruggemann, R. T. Buffler, M. M. M. Guillaume et al., "Stratigraphy, palaeoenvironments and model for the deposition of the Abdur Reef Limestone: context for an important archaeological site from the last interglacial on the Red Sea coast of Eritrea," Palaeogeography, Palaeoclimatology, Palaeoecology, vol. 203, no. 3-4, pp. 179-206, 2004.

[118] V. Rots and P. Van Peer, "Early evidence of complexity in lithic economy: core-axe production, hafting and use at late
Middle Pleistocene site 8-B-11, Sai Island (Sudan)," Journal of Archaeological Science, vol. 33, no. 3, pp. 360-371, 2006.

[119] M. J. Mehlman, "Provenience, age and associations of archaic Homo sapiens crania from Lake Eyasi, Tanzania," Journal of Archaeological Science, vol. 14, no. 2, pp. 133-162, 1987.

[120] H. J. Deacon and J. Deacon, Human Beginnings in South Africa: Uncovering the Secrets of the Stone Age, Altamira Press, 1999.

[121] K. Nicoll, "Geomorphic Development and Middle Stone Age Archaeology of the Lower Cunene River, Namibia-Angola Border," Quaternary Science Reviews, vol. 29, pp. 1419-1431, 2010.

[122] E. C. Fisher, M. Bar-Matthews, A. Jerardino, and C. W. Marean, "Middle and Late Pleistocene paleoscape modeling along the southern coast of South Africa," Quaternary Science Reviews, vol. 29, pp. 1382-1398, 2010.

[123] E. Thompson, H. M. Williams, and T. Minichillo, "Middle and late Pleistocene Middle Stone Age lithic technology from Pinnacle Point 13B (Mossel Bay, Western Cape Province, South Africa)," Journal of Human Evolution, vol. 59, no. 3-4, pp. 358-377, 2010.

[124] B. J. Schoville, "Frequency and distribution of edge damage on Middle Stone Age lithic points, Pinnacle Point 13B, South Africa," Journal of Human Evolution, vol. 59, no. 3-4, pp. 378391, 2010.

[125] K. S. Brown, C. W. Marean, A. I. R. Herries et al., "Fire as an engineering tool of early modern humans," Science, vol. 325, no. 5942, pp. 859-862, 2009.

[126] C. W. Marean, M. Bar-Matthews, E. Fisher et al., "The stratigraphy of the Middle Stone Age sediments at Pinnacle Point Cave 13B (Mossel Bay, Western Cape Province, South Africa)," Journal of Human Evolution, vol. 59, no. 3-4, pp. 234-255, 2010.

[127] R. Grün, P. Beaumont, P. V. Tobias, and S. Eggins, "On the age of Border Cave 5 human mandible," Journal of Human Evolution, vol. 45, no. 2, pp. 155-167, 2003.

[128] A. Bouzouggar, N. Barton, M. Vanhaeren et al., "82,000Year-old shell beads from North Africa and implications for the origins of modern human behavior," Proceedings of the National Academy of Sciences of the United States of America, vol. 104, no. 24, pp. 9964-9969, 2007.

[129] M. I. Bird, L. K. Fifield, G. M. Santos et al., "Radiocarbon dating from 40 to $60 \mathrm{ka} \mathrm{BP}$ at Border Cave, South Africa," Quaternary Science Reviews, vol. 22, no. 8-9, pp. 943-947, 2003.

[130] G. H. Miller, P. B. Beaumont, H. J. Deacon, A. S. Brooks, P. E. Hare, and A. J. T. Jull, "Earliest modern humans in southern Africa dated by isoleucine epimerization in ostrich eggshell," Quaternary Science Reviews, vol. 18, no. 13, pp. 1537-1548, 1999.

[131] A. G. M. Sinclair, "The MSA stone Tool Assemblage from the Cave of Hearths, Beds 4-9," in The Cave of Hearths: Makapan Middle Pleistocene Research Project, J. McNabb and A. G. M. Sinclair, Eds., University of Southampton Series in Archaeology 1, pp. 105-137, Archaeopress, Oxford, UK, 2009.

[132] C. W. Marean, "Pinnacle Point Cave 13B (Western Cape Province, South Africa) in context: the Cape Floral kingdom, shellfish, and modern human origins," Journal of Human Evolution, vol. 59, no. 3-4, pp. 425-443, 2010.

[133] A. J. D. Meiring, "The Macrolithic culture of Florisbad. Researches of the National Museum," Bloemfontein, vol. 1, pp. 205-237, 1956. 
[134] S. C. Reynolds, R. J. Clarke, and K. A. Kuman, "The view from the Lincoln Cave: mid- to late Pleistocene fossil deposits from Sterkfontein hominid site, South Africa," Journal of Human Evolution, vol. 53, no. 3, pp. 260-271, 2007.

[135] C. Ogola, The Sterkfontein Western BReccias: stratigraphy, fauna and artefacts, Ph.D. thesis, University of the Witwatersrand, South Africa, 2009.

[136] M. B. Sutton, T. R. Pickering, R. Pickering et al., "Newly discovered fossil- and artifact-bearing deposits, uraniumseries ages, and Plio-Pleistocene hominids at Swartkrans Cave, South Africa," Journal of Human Evolution, vol. 57, no. 6, pp. 688-696, 2009.

[137] D. J. de Ruiter, J. K. Brophy, P. J. Lewis, S. E. Churchill, and L. R. Berger, "Faunal assemblage composition and paleoenvironment of Plovers Lake, a Middle Stone Age locality in Gauteng Province, South Africa," Journal of Human Evolution, vol. 55, no. 6, pp. 1102-1117, 2008.

[138] L.S. Barham, M. J. Simms, M. Gilmour, and N. Debenham, "Twin Rivers, excavation and behavioural record," in The Middle Stone Age of Zambia, L. S. Barham, Ed., pp. 165-216, Bristol Western Academic \& Specialist Press, 2000.

[139] L. S. Barham, "Systematic pigment use in the middle pleistocene of south-central Africa," Current Anthropology, vol. 43, no. 1, pp. 181-190, 2002.

[140] H. J. Deacon, "Demography, subsistence, and culture during the Acheulian in southern Africa," in After the Australopithecines: Straigraphy, Ecology and Culture Change in the Middle Plesitocene, K. W. Butzer and G. L. L. Isaac, Eds., pp. 543-569, de Gruyter Mouton, 1975.

[141] L. Barham, "Backed tools in Middle Pleistocene central Africa and their evolutionary significance," Journal of Human Evolution, vol. 43, no. 5, pp. 585-603, 2002.

[142] A. W. Louw, "Bushman Rock Shelter, Ohrigstad, Eastern. Transvaal, a preliminary investigation," The South African Archaeological Bulletin, vol. 24, pp. 39-51, 1965.

[143] P. J. Sheppard and M. R. Kleindienst, “Technological change in the earlier and middle stone Age of Kalambo Falls (Zambia)," African Archaeological Review, vol. 13, no. 3, pp. 171-196, 1996.

[144] J. D. Clark, Kalambo Falls Prehistoric Site Volume 1: The Geology, Palaeoecology, And Detailed Stratigraphy of The Excavations, Cambridge University Press, 1974.

[145] L. S. Barham, G. Duller, A. Plater, S. Tooth, and S. Turner, "Recent excavations at Kalambo Falls, Zambia," Antiquity, vol. 833, p. 322, Project gallery, 2009.

[146] P. Kiberd, "Bundu farm: a report on archaeological and palaeoenvironmental assemblages from a pan site in Bushmanland, Northern Cape, South Africa," South African Archaeological Bulletin, vol. 61, no. 184, pp. 189-201, 2006.

[147] M. Chazan and L. K. Horwitz, "Milestones in the development of symbolic behaviour: a case study from Wonderwerk Cave, South Africa," World Archaeology, vol. 41, no. 4, pp. 521-539, 2009.

[148] N. Porat, M. Chazan, R. Grün, M. Aubert, V. Eisenmann, and L. K. Horwitz, "New radiometric ages for the Fauresmith industry from Kathu Pan, southern Africa: implications for the Earlier to Middle Stone Age transition," Journal of Archaeological Science, vol. 37, no. 2, pp. 269-283, 2010.

[149] J. Wilkins, L. Pollarolo, and K. Kuman, "Prepared core reduction at the site of Kudu Koppie in northern South Africa: temporal patterns across the Earlier and Middle Stone Age boundary," Journal of Archaeological Science, vol. 37, no. 6, pp. 1279-1292, 2010.
[150] H. Kempson, Late Earlier Stone Age sites in the Mapungubwe National Park, South Africa: a technological study, M.S. thesis, University of the Witwatersrand, South Africa, 2008.

[151] H. J. Deacon, "The Acheulian occupation at Amanzi Springs, Uitenhage, Cape Province," Annals of the Cape provincial Museums, vol. 8, pp. 89-189, 1970.

[152] G. J. Fock, "Rooidam: a sealed site of the First Intermediate," South African Journal of Science, vol. 64, pp. 153-159, 1968.

[153] B. J. Szabo and K. W. Butzer, "Uranium-series dating of lacustrine limestones from pan deposits with final Acheulian assemblage at Rooidam, Kimberley district, South Africa," Quaternary Research, vol. 11, no. 2, pp. 257-260, 1979.

[154] K. Kuman, "An Acheulian Factory Site with Prepared Core Technology near Taung, South Africa," The South African Archaeological Bulletin, vol. 56, pp. 8-22, 2001.

[155] I. Plug, "Some research results on the late Pleistocene and early Holocene deposits of Bushman Rock Shelter, eastern Transvaal," The South African Archaeological Bulletin, vol. 36, pp. 14-21, 1981.

[156] V. P. Liubin and F. Y. Guédé, "Paleolit Respubliki Kot d'Ivuar (Zapadnaya Afrika)," Institute of the History of Material Culture Proceedings, vol. 3, 2000.

[157] T. P. Volman, "Early prehistory of Southern Africa," in South African Prehistory and Palaeoenvironments, R. G. Klein, Ed., pp. 169-220, A. A. Balkema, Rotterdam, The Netherlands, 1984.

[158] N. Goren-Inbar and I. Saragusti, "An Acheulian biface assemblage from Gesher Benot Ya'aqov, Israel: indications of African affinities," Journal of Field Archaeology, vol. 23, pp. 15-30, 1996

[159] G. Sharon, "Acheulian giant-core technology: a worldwide perspective," Current Anthropology, vol. 50, no. 3, pp. 335367, 2009.

[160] W. J. Rink and H. P. Schwarcz, "Short contribution: ESR and uranium series dating of teeth from the lower Paleolithic site of Gesher Benot Ya'aqov Israel: confirmation of paleomagnetic age indications," Geoarchaeology, vol. 20, no. 1, pp. 5766, 2005.

[161] C. C. Gilbert and F. E. Grine, "Morphometric variation in the papionin muzzle and the biochronology of the South African Plio-Pleistocene karst cave deposits," American Journal of Physical Anthropology, vol. 141, no. 3, pp. 418-429, 2010.

[162] N. Alperson-Afil, G. Sharon, M. Kislev et al., "Spatial organization of hominin activities at gesher benot ya'aqov, Israel," Science, vol. 326, no. 5960, pp. 1677-1680, 2009.

[163] B. Martínez-Navarro and R. Rabinovich, "The fossil Bovidae (Artiodactyla, Mammalia) from Gesher Benot Ya'aqov, Israel: out of Africa during the Early-Middle Pleistocene transition," Journal of Human Evolution, vol. 60, no. 4, pp. 375-386, 2011.

[164] J. E. T. Channell, D. A. Hodell, B. S. Singer, and C. Xuan, "Reconciling Astrochronological and 40Ar/39Ar Ages for the Matuyama-Brunhes Boundary and Late Matuyama Chron," Geochemistry Geophysics Geosystems, vol. 11, no. 12, p. art. no. Q0AA12, 2010.

[165] M. C. J. de Wit, "Canteen Koppie at Barkly West: South Africa's first diamond mine," South African Journal of Geology, vol. 111, no. 1, pp. 53-66, 2008.

[166] J. P. Raynal, F. Z. Sbihi Alaoui, D. Geraads, L. Magoga, and A. Mohi, "The earliest occupation of North-Africa: the Moroccan perspective," Quaternary International, vol. 75, pp. 65-75, 2001.

[167] J. R. Smith, R. Giegengack, H. P. Schwarcz et al., "A reconstruction of Quaternary pluvial environments and human 
occupations using stratigraphy and geochronology of fossilspring tufas, Kharga Oasis, Egypt," Geoarchaeology, vol. 19, no. 5, pp. 407-439, 2004.

[168] M. N. Haidle and A. F. Pawlik, "The earliest settlement of Germany: Is there anything out there?” Quaternary International, vol. 223-224, pp. 143-153, 2010.

[169] E. Werker, "780,000-Year-old wood from Gesher Benot Ya'aqov, Israel," Israel Journal of Plant Sciences, vol. 54, no. 4, pp. 291-300, 2006.

[170] R. R. Inskeep, The peopling of southern Africa .Cape Town, D. Philip, London, UK, 1978.

[171] R. G. Klein, "Problems in the Study of the Middle Stone Age of South Africa," The South African Archaeological Bulletin, vol. 25, pp. 127-135, 1970.

[172] C. G. Sampson, "The Middle Stone Age industries of the Orange River Scheme area," Memoirs of the National Museum (Bloemfontein), vol. 4, 1969. 

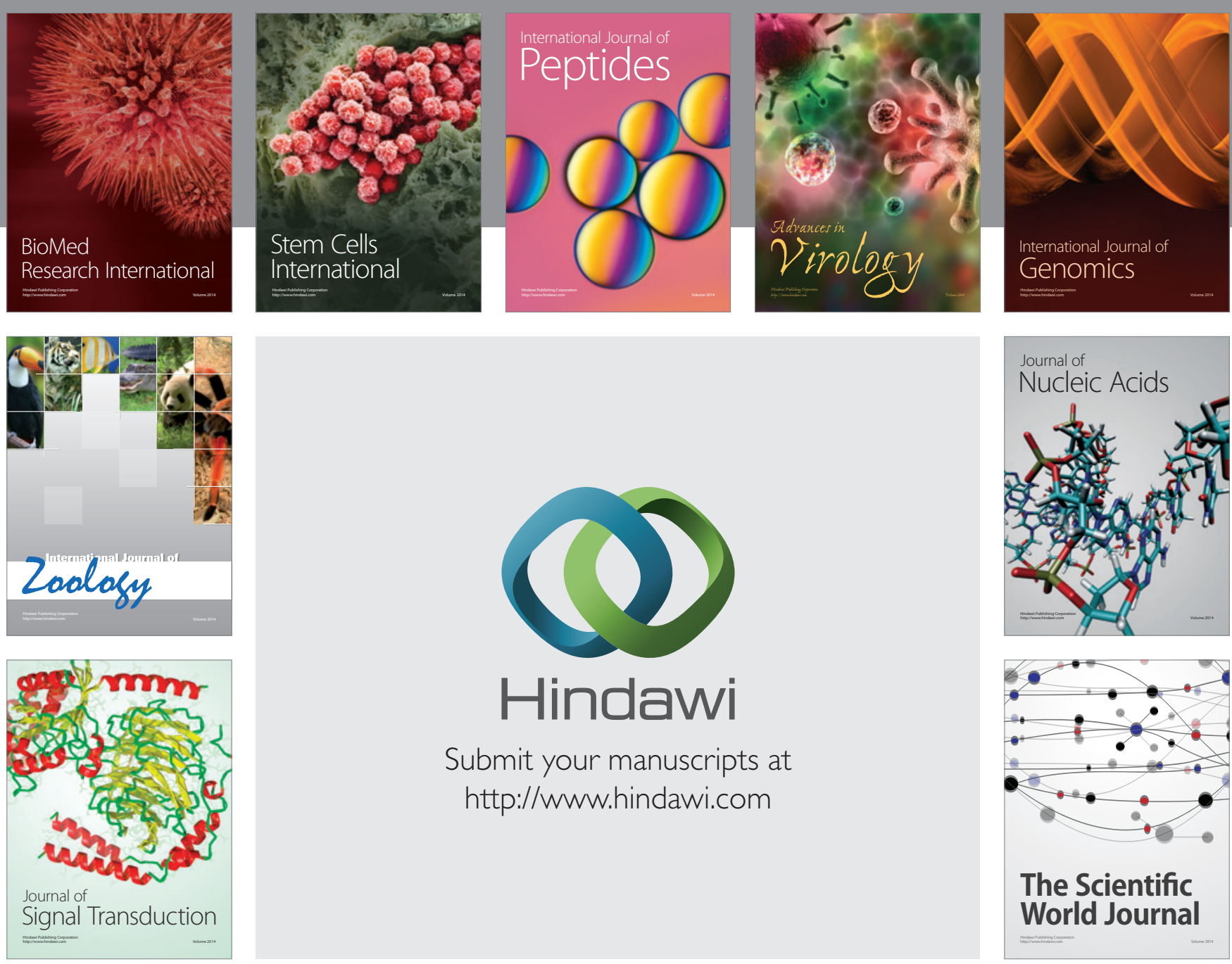

Submit your manuscripts at

http://www.hindawi.com
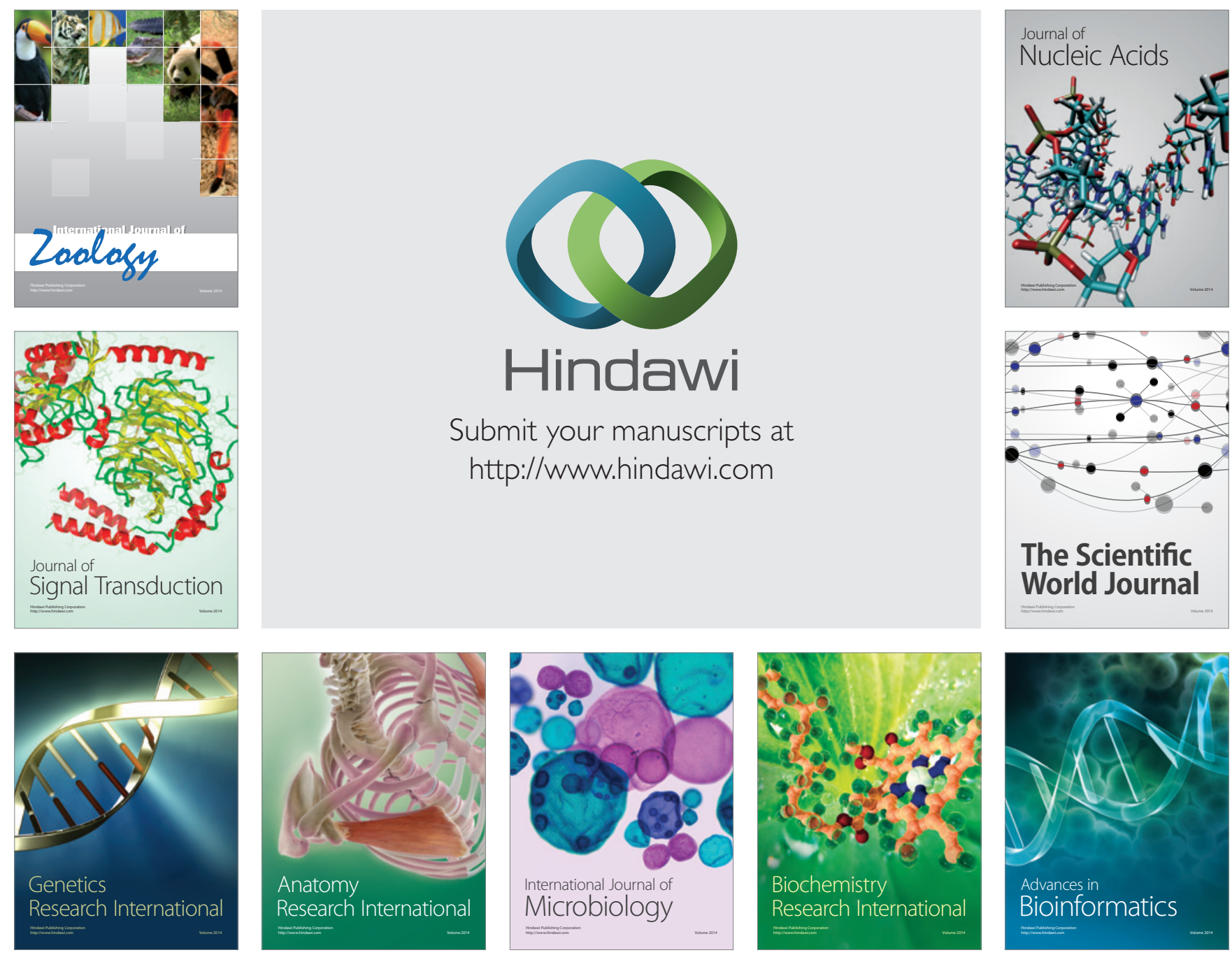

The Scientific World Journal
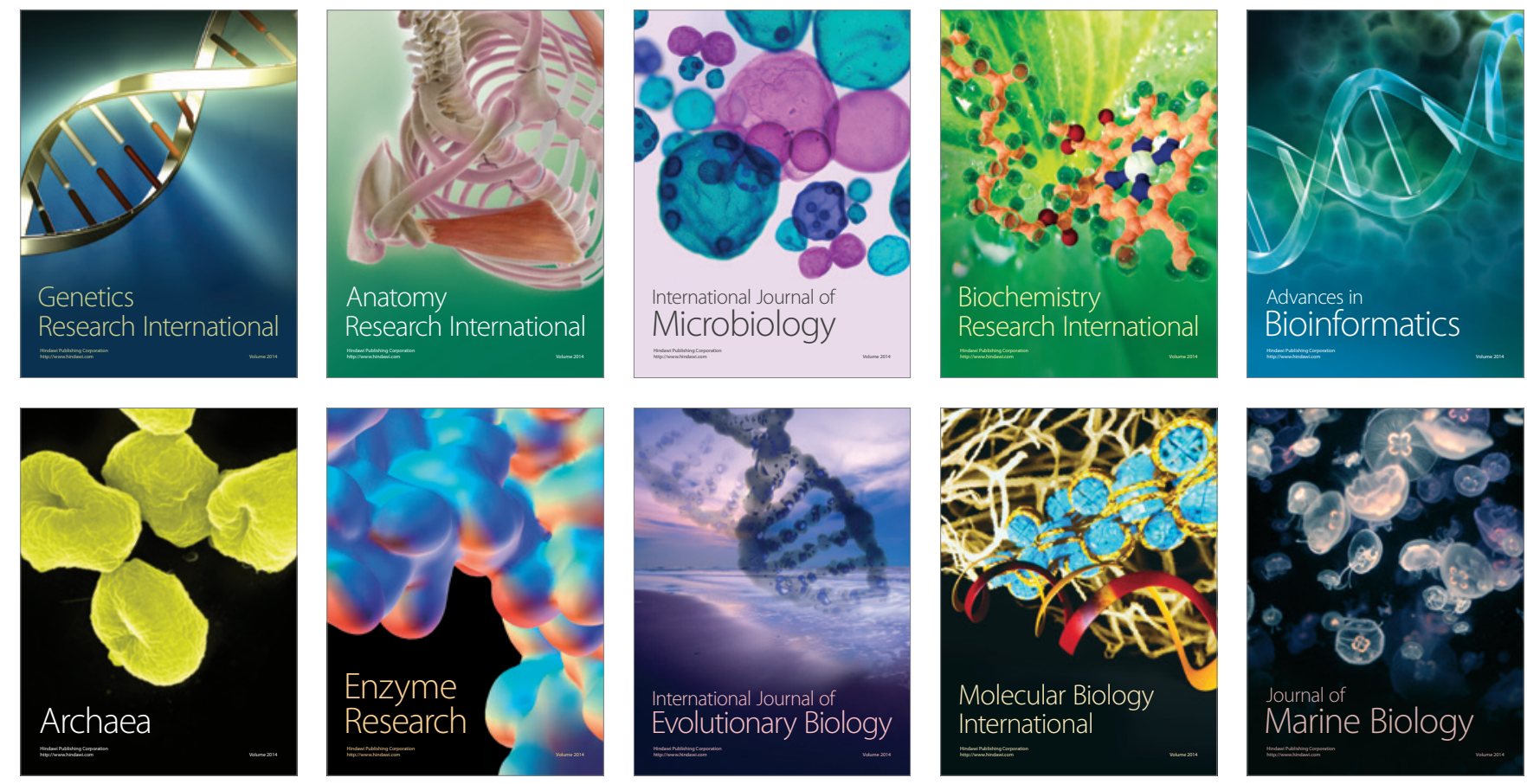